\title{
Hypoxic Preconditioned Bone Marrow-Derived Mesenchymal Stromal/Stem Cells Enhance Myoblast Fusion and Skeletal Muscle Regeneration
}

\section{Karolina Archacka}

University of Warsaw: Uniwersytet Warszawski

Iwona Grabowska

University of Warsaw: Uniwersytet Warszawski

Bartosz Mierzejewski

University of Warsaw: Uniwersytet Warszawski

Joanna Graffstain

University of Warsaw: Uniwersytet Warszawski

Alicja Górzyńska

University of Warsaw: Uniwersytet Warszawski

Marta Krawczyk

University of Warsaw: Uniwersytet Warszawski

Anna M Różycka

University of Warsaw: Uniwersytet Warszawski

llona Kalaszczyńska

Medical University of Warsaw: Warszawski Uniwersytet Medyczny

Władysława Stremińska

University of Warsaw: Uniwersytet Warszawski

Katarzyna Jańczyk-llach

University of Warsaw: Uniwersytet Warszawski

Piotr Walczak

Johns Hopkins University

Mirosław Janowski

University of Maryland School of Medicine

Maria Anna Ciemerych

University of Warsaw: Uniwersytet Warszawski

Edyta Brzoska ( $\nabla$ edbrzoska@biol.uw.edu.pl )

Uniwersytet Warszawski https://orcid.org/0000-0002-7886-0436 
Keywords: BM-MSC, fusion, hypoxic, normoxic, migration, myogenic differentiation

Posted Date: May 3rd, 2021

DOI: https://doi.org/10.21203/rs.3.rs-474083/v1

License: (c) (1) This work is licensed under a Creative Commons Attribution 4.0 International License. Read Full License

Version of Record: A version of this preprint was published at Stem Cell Research \& Therapy on August 9th, 2021. See the published version at https://doi.org/10.1186/s13287-021-02530-3. 
Hypoxic preconditioned bone marrow-derived mesenchymal stromal/stem cells enhance myoblast fusion and skeletal muscle regeneration

Archacka Karolina ${ }^{1^{*}}$, Grabowska Iwona ${ }^{1^{*}}$, Mierzejewski Bartosz ${ }^{1}, G$ raffstein Joanna ${ }^{1}$, Górzyńska Alicja ${ }^{1}$, Krawczyk Marta ${ }^{1}$, Różycka Anna M. ${ }^{1}$, Kalaszczyńska llona ${ }^{2,3}$, Stremińska Władysława ${ }^{1}$, Jańczyk-Ilach Katarzyna ${ }^{1}$, Walczak Piotr ${ }^{4,5}$, Janowski ${ }^{6,7}$ Mirosław, Ciemerych Maria A. ${ }^{1}$, Brzoska Edyta $^{1 \Delta}$

*equal authors

${ }^{\Delta}$ corresponding author

${ }^{1}$ Department of Cytology, Institute of Developmental Biology and Biomedical Sciences, Faculty of Biology, University of Warsaw, Miecznikowa 1 St, 02-096 Warsaw, Poland

${ }^{2}$ Department of Histology and Embryology, Medical University of Warsaw, 02-004 Warsaw, Poland ${ }^{3}$ Laboratory for Cell Research and Application, Medical University of Warsaw, 02-097 Warsaw, Poland ${ }^{4}$ Department of Pathophysiology, Faculty of Medical Sciences, University of Warmia and Mazury, Warszawska 30 St, 10-082 Olsztyn, Poland

${ }^{5}$ Russell H. Morgan Department of Radiology and Radiological Science, Division of MR Research, the Johns Hopkins University School of Medicine, Baltimore, MD, 21205, USA

${ }^{6}$ Center for Advanced Imaging Research, Department of Diagnostic Radiology and Nuclear Medicine, University of Maryland, Baltimore, MD, 21201, USA

${ }^{7}$ NeuroRepair Department, Mossakowski Medical Research Centre, Polish Academy of Sciences, Pawinskiego 5 St, 02-106 Warsaw, Poland

email addresses:

\begin{tabular}{|l|l|}
\hline Archacka Karolina & kczaja@biol.uw.edu.pl \\
\hline Grabowska Iwona & igrabowska@biol.uw.edu.pl \\
\hline Mierzejewski Bartosz & bmierzejewski@biol.uw.edu.pl \\
\hline Graffstein Joanna & j.graffstein@student.uw.edu.pl \\
\hline Górzyńska Alicja & ala.gorzynska@gmail.com \\
\hline Krawczyk Marta & marta.krawczyk@wum.edu.pl \\
\hline Różycka Anna M & a.rozycka6@student.uw.edu.pl \\
\hline Kalaszczyńska Ilona & ilona.kalaszczynska@wum.edu.pl \\
\hline Stremińska Władysława & krymar@biol.uw.edu.pl \\
\hline Jańczyk-Ilach Katarzyna & kilach@biol.uw.edu.pl \\
\hline Walczak Piotr & pwalczak@mri.jhu.edu \\
\hline Janowski Mirosław & neuroibis@gmail.com \\
\hline Ciemerych Maria A & ciemerych@biol.uw.edu.pl \\
\hline Brzoska Edyta & edbrzoska@biol.uw.edu.pl \\
\hline
\end{tabular}

short title: Hypoxic impacts BM-MSC differentiation

key words: BM-MSC, fusion, hypoxic, normoxic, migration, myogenic differentiation 


\section{Abstract}

Background: The skeletal muscle reconstruction occurs thanks to unipotent stem cells, i.e., satellite cells. The satellite cells remain quiescent and localized between myofiber sarcolemma and basal lamina. They are activated in response to muscle injury, proliferate, differentiate into myoblasts, and recreate myofibers. Many stem and progenitor cells support skeletal muscle regeneration, which could be disturbed by extensive damage, sarcopenia, cachexia, or genetic diseases like dystrophy. Many lines of evidence showed that the level of oxygen regulates the course of cell proliferation and differentiation. Methods: In the present study, we analyzed hypoxic's impact on human and pig bone marrow-derived mesenchymal stromal cell (MSC) and mouse myoblast proliferation, differentiation, and fusion. Moreover, the influence of the transplantation of human bone marrow-derived MSCs cultured under hypoxic conditions on skeletal muscle regeneration was studied. Results: We showed that bone marrowderived MSCs increased VEGF expression and improved myogenesis under hypoxic conditions in vitro. Transplantation of hypoxic preconditioned bone marrow-derived MSCs into injured muscles resulted in the improved cell engraftment and formation of new vessels. Conclusions: We suggested that SDF-1 and VEGF secreted by hypoxic preconditioned bone marrow-derived MSCs played an essential role in cell engraftment and angiogenesis. Importantly, hypoxic preconditioned bone marrow-derived MSCs more efficiently engrafted injured muscles, however, they did not undergo myogenic differentiation. 


\section{Introduction}

Skeletal muscle regeneration is a complex process that allows restoration of skeletal muscle homeostasis lost due to the injury, such as intensive exercise, surgical procedures, and diseases. Skeletal muscle regeneration covers two distinct phases. The first one includes tissue degeneration, accompanied by inflammation, necrosis of damaged myofibers, and their phagocytosis by immune cells. The second one is regeneration, leading to new myofiber formation followed by their maturation, tissue reinnervation, and finally skeletal muscle functional recovery (1).

Muscle necrosis occurs when myofibers' integrity is severely disrupted what involves increased sarcolemma permeability, organelle dysfunction, and loss of myofiber architecture. Necrotic cell death and loss of plasmalemma integrity lead to the release of intracellular components that act as damageassociated molecular patterns (DAMPs) and trigger an inflammatory response $(2,3)$. Necrotic myofibers release many cytokines, growth factors, and chemoattractants. These signals activate tissue-resident and circulating inflammatory cells $(4,5)$. Neutrophils are the first to infiltrate the site of injury. These cells phagocytize damaged myofibers and release numerous factors which induce migration of local monocytes and their differentiation into macrophages (6-8). Two days after injury, macrophages become the predominant cell population present within damaged tissue $(5,9,10)$. They can be divided into two distinct subpopulations - M1, also considered as pro-inflammatory macrophages, characterized by the presence of CD68, and responsible for phagocytosis of necrotic tissue and releasing

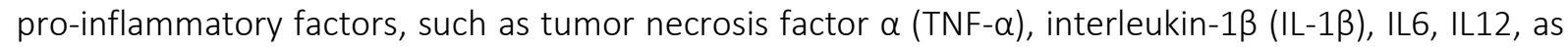
well as nitric oxide (NO) and reactive oxygen species (ROS) (11-13). The second described population is M2, also called anti-inflammatory macrophages, characterized by the presence of CD163, releasing factors, like tumor growth factor $\beta$ (TGF- $\beta$ ), IL4, IL10 or IL13, and for supporting myoblast differentiation, angiogenesis, and extracellular matrix (ECM) deposition $(14,15)$. The next phase of skeletal muscle repair covers myofiber regeneration which is possible due to satellite cells (SCs) - skeletal musclespecific stem cells, characterized by a PAX7 transcription factor. These cells are tightly connected to the myofibers and located between basal lamina and sarcolemma. In healthy muscles, SCs remain quiescent, but after injury, they become activated, re-enter the cell cycle, start to proliferate, differentiate into myoblasts which further fuse to form myotubes. Finally, myotubes' maturation leads to new functional myofibers' formation $(7,16-18)$.

Quiescent SCs can quickly respond to changes in their niche and specific signals present in their microenvironment. Among the crucial factors causing SC activation and proliferation are mechanical disruptions of sarcolemma and action of growth factors released by inflammatory cells, endothelial cells, interstitial cells, such as fibroblasts, or released from the ECM by specialized proteases - 
metalloproteinases (MMPs) $(19,20)$. Fibroblast growth factor (FGF) is one such factor. Its action via transient receptor potential channels (TRPC) leads to the translocation of nuclear factor of activated Tcells (NFATc) into the nucleus resulting in SC activation (21, 22). FGF action is also known to activate the p38 mitogen-activated protein kinase (p38 MAPK) pathway, which acts as a molecular switch during SC activation (23). Another ECM-derived factor crucial for SC activation is hepatocyte growth factor (HGF), which binding to hepatocyte growth factor receptor (HGFR/c-Met) promotes SC re-entry into the cell cycle (24). One of the signals produced by such cells as fibroblasts or myofibers is insulin-like growth factor 1 (IGF-1), which is well known to stimulate the PI3K/Akt/mTOR pathway and to downregulate the activity of transcription factor Forkhead box O (FOXO), what in consequence leads to downregulation of p27 cell cycle inhibitor and activation of SC cell cycle (25). Some of the previously mentioned factors are known to directly or indirectly regulate SC activation and proliferation. Among them are, for example, TNF- $\alpha$ activating nuclear factor kappa B (NF-KB) pathway, which leads to silencing Notch1, NO which stimulates MMP expression and ECM remodeling or IL6, which stimulates SC proliferation in signal transducer and activator of transcription 3 (STAT3)-dependent manner (19, 26-28). Finally, activated and proliferating SCs start to differentiate.

The myogenic differentiation of SCs is regulated by sequentially expressed transcription factors, called myogenic regulatory factors (MRFs). MRF family consists of MYF5, MYOD, myogenin, and MRF4 $(29,30)$. Quiescent SCS are characterized by the presence of paired box transcription factor 7 (PAX7). PAX7 and MYF5 are present in proliferating SCs and myoblasts. PAX7 regulates the expression of MYF5 and MYOD, while MYF5 presence enhances the expression of MYOD. MYOD is a critical factor of myogenic differentiation. It facilitates the transition from myoblast proliferation to the myocyte differentiation stage by inducing the myogenin and p21 and p57 cell cycle inhibitor expression $(31,32)$. Further, MYOD and myogenin trigger the expression of other genes essential for muscle cell function, such as MRF4, myosin heavy and light chains, muscle creatine kinase, or troponin (33). The expression of myogenin and MRF4 is accompanied by the downregulation of PAX7, MYF5, and MYOD. Some cells do not undergo differentiation but remain PAX7 positive, downregulate MYOD, and restore the SC population necessary for the next rounds of muscle regeneration (34-36). Those that differentiated fuse to each other to result in the formation of multinucleated myotubes and then myofibers $(37,38)$. Alternatively, differentiated myocytes can fuse with already existing myofibers during the regeneration of slightly damaged skeletal muscles (39). Finally, newly formed myotubes and myofibers undergo maturation to become fully functional. During maturation, myofibers grow, myofibers' proper contractility is restored, and neuro-muscular junctions are formed $(40,41)$. 
In skeletal muscle diseases, sarcopenia, or cachexia, skeletal muscle regeneration is disturbed. Many populations of stem and progenitor cells are studied for potential therapeutic use. Two main strategies to support skeletal muscle regeneration are considered. First, the transplanted cells could participate in myofiber reconstruction; second, transplanted cells' secreted factors could support regeneration. One of the studied cells are bone marrow-derived stromal cells, also known as bone marrow-derived "mesenchymal" stem/stromal cells (bone marrow-derived MSCs). However, it should be noted that these cells do not present naïve myogenic potential (42). Bone marrow-derived MSCs are a heterogeneous population (43), typically isolated from bone marrow based on their ability to adhere to the culture plate's surface. It was proven that bone marrow-derived MSCs contain a population of cells that fulfill the rigorous criteria of stem cells (44). This subpopulation of bone marrow-derived MSCs present long-term expansion without phenotypic change, self-renewal probed during in vivo serial transplantations, and multipotency examined by in vivo differentiation assay at the single-cell level (4448). CD146 appeared to be a handy marker to select and isolate stem cell subpopulations from bone marrow-derived MSCs (45). Human CD146+ bone marrow-derived MSCs were shown to be able to selfrenew, differentiate into bone and bone marrow, a support organization of endothelial cells into functional blood vessels, and differentiate into chondrocytes and adipocytes $(45,49)$.

As we mentioned above, bone marrow-derived MSCs do not present naïve myogenic potential (45). These cells do not fuse in the absence of myoblasts and rarely fuse with myoblasts in co-cultures $(45,50-53)$. However, bone marrow-derived MSCs could follow myogenic differentiation as the result of reprogramming induced by 5 -azacytidine treatment, overexpression of Notch intracellular domain (NICD), paired box transcription factor 3 (Pax3), or constitutively active $\beta$-catenin, or as a result of 3D co-culture with myofibers (54-59). It was also documented that bone marrow-derived MSCs could support skeletal muscle regeneration; however, these cells rarely participate in new myofiber formation $(50,59-64)$.

In the current study, we focused on the hypoxic effect on bone marrow-derived MSC and myoblast co-cultures. We also followed if cultured under hypoxic condition bone marrow-derived MSCs could more efficiently support skeletal muscle regeneration. The level of oxygen is an essential factor regulating gene transcription and cell fate. The level of $\mathrm{O}_{2}$ during in vitro culture under hypoxic conditions (1-3\%) is much more similar to the level present in the physiological bone marrow-derived MSC niche in the bone marrow (2-7\%) than that observed under standard in vitro culture conditions. Accordingly, it was previously shown that bone marrow-derived MSCs cultured under hypoxic conditions induced their proliferation, migration, elevated colony-forming unit capabilities, increased ECM deposition, osteogenic and adipogenic potential, and angiogenic factors expression (65-71). 
Moreover, preconditioning of bone marrow-derived MSC with hypoxic increased their ability to engraft injured tissues after transplantation. In the subacute murine limb ischemia model, hypoxic preconditioned bone marrow-derived MSCs injected into skeletal muscles engrafted this tissue more efficiently, induced neoangiogenesis, and improved blood flow (69). Similar results were observed after transplantation of hypoxic preconditioned bone marrow-derived MSCs to other ischemic tissues, including heart, brain, lung, and liver (70-74). We hypothesized that hypoxic preconditioning impacts the human bone marrow-derived MSC secretome. As a result, these cells could more efficiently engraft injured skeletal muscle, support myoblast fusion, and skeletal muscle regeneration. To follow this problem, we choose to investigate human and pig bone marrow-derived MSCs. We selected cells of two species as we previously showed that as far as MSCs are concerned, the cells' origin may determine their reaction to the same factors (75). Moreover, pig serves as a valuable model in preclinical research. We analyzed human and pig bone marrow-derived MSCs in vitro, co-culture with mouse myoblasts, and in vivo after their transplantation to mouse injured skeletal muscles.

\section{Materials and Methods}

Primary myoblasts, C2C12, and MSCs culture under normoxic and hypoxic conditions

Four different cell types were used during experiments. Human bone marrow-derived mesenchymal stromal cells (hMSCs) were obtained from Lonza (Lonza PT-2501). Fetal pig bone marrowderived mesenchymal stromal cells (pMSCs) were kindly provided by dr. Joanna Wojtkiewicz from University of Warmia and Mazury in Olsztyn. pMSCs were isolated from transgenic pigs, which constitutively expressed green fluorescent protein (GFP). Both types of MSCs were cultured in Dulbecco's modified Eagle's medium (DMEM; ThermoFisher Scientific) containing glucose $4.5 \mathrm{~g} / \mathrm{l}$ supplemented with 15\% inactivated fetal bovine serum (FBSin; ThermoFisher Scientific) and 0,1\% gentamycin solution (Sigma-Aldrich), further referred to as MSC medium (MSCmed). C2C12 cells (Sigma-Aldrich) were cultured in DMEM containing glucose $4.5 \mathrm{~g} / \mathrm{l}$, supplemented with $10 \%$ FBSin and 1\% penicillin-streptomycin solution (ThermoFisher Scientific), further referred to as C2C12 medium (C2C12med). Mouse primary myoblasts (mPM) were isolated from tibialis anterior (TA), soleus, extensor digitorum longus (EDL), and flexor digitorum brevis (FDB) muscles of 2-3-month-old C57/BL6 male mice using Bischoff and Rosenblatt method $(76,77)$. Briefly, muscles were isolated from tendon to tendon, digested in $0.2 \%$ collagenase type I (Sigma-Aldrich) solution in DMEM. Then, single myofibers were collected in suspension, passed through a $21 \mathrm{G}$ syringe needle, and filtered through a $40 \mu \mathrm{m}$ strainer. Primary myoblasts were cultured in DMEM containing glucose $1 \mathrm{~g} / \mathrm{l}$, supplemented with $10 \%$ horse serum (HS; ThermoFisher Scientific), 20\% FBSin, 0.5\% chicken embryo extract (CEE; ThermoFisher Scientific), and 1\% penicillin-streptomycin solution, further referred to as PM medium (PMmed). All cell types were cultured in normoxic $\left(37^{\circ} \mathrm{C}, 21 \% \mathrm{O}_{2}, 5 \% \mathrm{CO}_{2}\right)$ or hypoxic $\left(37^{\circ} \mathrm{C}, 5 \% \mathrm{O}_{2}, 5 \% \mathrm{CO}_{2}\right)$. 
Migration assay - scratch assay

Migration of pMSCs or hMSCs cultured either under hypoxic or normoxic was analyzed using scratch wound healing assay (78). Briefly, cells were cultured to obtain $90-100 \%$ confluence. Next, the cells were scratched from the plate using a plastic tip to create the "wound". The wound healing manifested by the ability of the cells to refill the created gap was observed. After $3.5 \mathrm{~h}, 8 \mathrm{~h}$ and $24 \mathrm{~h}$ cells were fixed with cold methanol and stained using Giemsa-May Grünwald method. The pictures were taken, and the area of the scratch was calculated using GIMP 2.

Myoblast and bone marrow-derived MSC co-culture, fusion index, and hybrid myotube analysis

Co-cultures were obtained by seeding mPM in a 1:1 ratio with either pMSCs or hMSCs. Cells were cultured under normoxic or hypoxic conditions in MSCmed or PMmed for 5-7 days. C2C12 myoblasts $\left(3 \times 10^{4}\right.$ or $\left.6 \times 10^{4}\right)$ were cultured in the absence of hMSCs or pMSCs or co-cultured with hMSCS or pMSCs in $3: 2.5 ; 3: 5 ; 3: 7.5$ ratio. Cells were cultured under normoxic or hypoxic conditions in C2C12med for 5-7 days. Further, cells were fixed, and fusion index or proportion of hybrid myotubes were estimated.

Fusion index of $\mathrm{C} 2 \mathrm{C} 12$ or mPM cultured alone or in co-cultures either with pMSCs or hMSCs was calculated. Briefly, differentiated cells were fixed in cold methanol and stained according to the GiemsaMay Grünwald method. Images from 4 fields of view were collected, and nuclei number was counted. Fusion index was calculated as a percentage of nuclei present in myotubes compared to all visible cell nuclei.

Myotubes formed by either C2C12 or PM co-cultured either with pMSCs or hMSCs were visualized using skeletal myosin's immunolocalization. The participation of hMSCs in myotube formation was evaluated by visualization of human nuclei. pMSC contribution in hybrid myotubes formation was verified by the presence of GFP within myotubes.

\section{Muscle injury and cell transplantation}

Local Ethics Committee No. 1 in Warsaw, Poland, approved all procedures involving animalspermission number: 669/2018. To induce skeletal muscle injury, 2-3-month-old NOD SCID mice (Janvier Labs) were anesthetized, and their Gastrocnemius muscles were injected with $50 \mu \mathrm{l}$ of $10 \mathrm{mM}$ cardiotoxin (L8102, Latoxan). Further, $0.5 \mathrm{mln}$ of hMSCs cultured in normoxic or hypoxic (for 48h) suspended in $20 \mu$ l of phosphate buffer saline (PBS) were injected into damaged Gastrocnemius muscle. 
In contrast, the contralateral leg was injected with $0.9 \% \mathrm{NaCl}$ solution (saline-treated muscles served as a control). After 14 days of regeneration, mice were sacrificed, muscles were isolated, and analyzed.

\section{Immunocytochemistry and immunohistochemistry}

Selected antigens were immunolocalized in in vitro cultured cells as well as in muscle crosssections. In vitro cell cultures were fixed with 3\% PFA, washed with PBS, and stored in $4^{\circ} \mathrm{C}$. Dissected skeletal muscles were frozen in isopentane, cooled down with liquid nitrogen, transferred to $-80^{\circ} \mathrm{C}$, and cut into $10 \mu \mathrm{m}$ sections using cryomicrotome (Microm HM, Thermo Fisher Scientific). Cryosections were fixed with $3 \%$ paraformaldehyde, washed with PBS, and stored in $4^{\circ} \mathrm{C}$. Further fixed cells or cryosections were permeabilized with $0.1 \%$ Triton X-100 (Sigma-Aldrich) in PBS and incubated with $0.25 \%$ glycine (Sigma-Aldrich) in PBS. Non-specific binding of antibodies was blocked with 3\% bovine serum albumin (BSA, Sigma-Aldrich) in PBS. Then cells or cryosections were incubated with primary antibodies diluted $1: 100$ in $3 \%$ BSA in PBS overnight. With appropriate secondary antibodies conjugated with fluorochromes diluted 1:200 in 1.5\% BSA in PBS for $2 \mathrm{~h}$ in room temperature. Next, samples were washed with PBS, and cell nuclei were visualized with Hoechst 33342 diluted 1:500 in 3\% BSA in PBS. Finally, specimens were mounted with Fluorescent Mounting Medium (Dako Cytomation). Samples were analyzed using Axiovert 100M LSM 510 (Zeiss) and ZEN software. The following primary antibodies were used: rabbit anti-mouse skeletal myosin (M7523; Sigma-Aldrich), mouse anti-human nuclear antigen (ab191181; Abcam), rabbit anti-laminin (L9393; Sigma-Aldrich). The following secondary antibodies were used: donkey anti-mouse conjugated with AlexaFluor 488 (A21202, ThermoFisher Scientific) or AlexaFluor 594 (A21203, ThermoFisher Scientific), goat anti-rabbit conjugated with AlexaFluor 488 (A11008, ThermoFisher Scientific), or donkey anti-rabbit conjugated with AlexaFluor 594 (A21207, ThermoFisher Scientific).

\section{Muscle histology}

Dissected skeletal muscles were frozen in isopentane, cooled down with liquid nitrogen, transferred to $-80^{\circ} \mathrm{C}$, and cut into $10 \mu \mathrm{m}$ sections using cryomicrotome (Microm HM, Thermo Fisher Scientific). Cryosections were fixed with $3 \%$ PFA, washed with PBS, and stored in $4^{\circ} \mathrm{C}$. Samples were hydrated in PBS, incubated in Harris hematoxylin solution (Sigma-Aldrich), and washed in distilled water. Then, fixed sections were incubated in eosin Y solution (Sigma-Aldrich) and washed in distilled water. Specimens were mounted with UltraMount (Dako Cytomation) and analyzed using inverted light microscope Eclipse TE200 (Nikon) and ImageJ software (NIH). 
Gene expression analysis

Total RNA was isolated from muscles, C2C12, mPM, pMSCs, and hMSCs cultured alone or in cocultures, using High Pure Isolation Kit (Roche) and from dissected muscles using mirVana ${ }^{\text {TM }}$ miRNA Isolation Kit (Thermo Fischer Scientific) and purified with Turbo DNA-free Kit (Thermo Fischer Scientific), according to the manufacturers' protocols. cDNA was obtained in reverse transcription reaction performed using RevertAid First Strand cDNA Synthesis Kit (ThermoFisher Scientific) according to manufacturer's protocol. The conditions of reverse transcription were as follows: $25^{\circ} \mathrm{C}$ for $10 \mathrm{~min}, 42^{\circ} \mathrm{C}$ for $60 \mathrm{~min}, 85^{\circ} \mathrm{C}$ for $5 \mathrm{~min}$. Next, mRNA levels were examined using quantitative real-time PCR analysis (qPCR) with TaqMan assays (ThermoFisher Scientific) for the following genes: human: CD9 (Hs00233521_m1), ADAM9 (Hs00177638_m1), CSPG4 (Hs00361541_g1), PDFGRB (Hs01019589_m1), VWF (Hs00169795_m1), KDR (Hs00911700_m1), CDH15 (Hs00170504_m1), MYOD1 (Hs02330075_g1), MYF5 (Hs00929416_g1), MYOG (Hs01072232_m1), MCAM (Hs00174838_m1), VCAM1 (Hs01003372_m1), NES (Hs04187831_g1), CXCL12 (Hs03676656_mH), VEGFA (Hs05484830_s1), WNT4 (Hs01573505_m1), FAP (Hs00990791_m1); pig: SGCA (Ss03821424_s1), ACTA1 (Ss04245853_m1), DES (Ss03378045_u1), MYOG (Ss03379073_u1); mouse: Adam9 (Mm01218460_m1), Cd9 (Mm00514255_g1), Cdh15 (Mm00483191_m1), Ncam1 (Mm01149710_m1), Vcam1 (Mm01320970_m1), Pax7 (Mm01354484_m1), Myf5 (Mm00435125_m1), Myod1 (Mm00440387_m1), Myog (Mm00440387_m1), Cxcl12 (Mm004485552_m1), Vegfa (Mm00437304_m1), Vwf (Mm00550376_m1), Kdr (Mm01222419_m1). HPRT/Hprt (Hs99999909_m1, Ss03382484_u1, Mm03024075_m1) was used as a reference gene for in vitro studies and actin (ACTB; Hs030233943_g1 and Mm01205647_g1) was used as reference gene for in vivo studies. All reactions were performed in duplicates. GPCR was performed with the TaqMan Gene Expression Master Mix (ThermoFisher Scientific) using LightCycler 480 (Roche) according to manufacturer's instruction. The conditions of qPCR were as follows: preincubation $2 \mathrm{~min} ., 50^{\circ} \mathrm{C}$; preincubation $10 \mathrm{~min} ., 95^{\circ} \mathrm{C}$; amplification (40 cycles) 15 s., $95^{\circ} \mathrm{C}$, and $1 \mathrm{~min}$. $60^{\circ} \mathrm{C}$. Expression levels were calculated with $2^{-(\Delta \mathrm{CT})}$ formula.

\section{Statistical analysis}

At least three independent biological experiments were shown as mean with standard deviations with GraphPad Prism 7. The results were analyzed in GraphPad Prism7 with the One-Way ANOVA test and Bonferroni multi comparison test or t-Student test (Figure 5). The results were compared to cells cultured in MSCmed under normoxic conditions. 


\section{Results}

The proliferation, migration, and fusion of human and pig bone marrow-derived MSCs, mouse primary myoblasts, and $\mathrm{C} 2 \mathrm{C} 12$ under normoxic and hypoxic conditions

First, we analyzed the proliferation of human bone marrow-derived mesenchymal stromal cells (hMSC), fetal pig bone marrow-derived mesenchymal stromal cells (pMSC), as well as mouse primary myoblasts (mPM), which we used to set up the co-culture experiments (Figure 1A). Next, we performed similar analyzes of hMSC or pMSC co-cultured with mPM or mouse C2C12 myoblasts. The two types of myoblasts were analyzed because of differences between primary cultures and cell lines. All these experiments were carried out either under normoxic or hypoxic conditions. Cells and co-cultures were analyzed after 5-7 days of culture in the following media types: MSCmed and either C2C12med or PMmed. MSCmed and $\mathrm{C} 2 \mathrm{C} 12 \mathrm{med}$ allowed studying the cells cultured under proliferating conditions and PMmed under differentiating conditions. Analysis of mPMs showed that their number was significantly higher in cultures carried under hypoxic conditions, regardless of the medium used. Neither hypoxic nor the type of medium influenced the number of hMSCs or pMSCs. Co-culture of mPMs with either hMSCs or pMSCs, conducted under hypoxic conditions, also increased overall cell number (Figure 1A). No significant change in hMSC or pMSC migration was noticed comparing normoxic and hypoxic conditions (Figure 1B.).

Second, we compared the fusion index and proportion of hybrid myotubes formed due to the fusion between either hMSCs or pMSCs with either mPM or C2C12 myoblasts. Depending on the experiment set, the co-cultures were conducted in MSCmed, C2C12med, or PMmed, in each case under normoxic or hypoxic conditions (Figure 2). First, we analyzed the fusion index of mPM (Figure 2A) or C2C12 myoblasts (Figure 2B). We noticed that hypoxic conditions significantly decreased myoblast fusion. Next, fusion was considerably higher when mPM and C2C12 were cultured under hypoxic conditions in the presence of either hMSCs or pMSCs. In the case of co-cultures conducted under normoxic, the presence of hMSCs did not impact the fusion index of mPM nor C2C12. Interestingly, pMSCs had a negative impact on $\mathrm{C} 2 \mathrm{C} 12$ myoblast fusion when cultured under normoxic conditions. The proportion of hybrid myotubes formed by mPM either with hMSCs or pMSCs significantly increased under hypoxic conditions (Figure 2C, D). The fusion of hMSCs or pMSCs and C2C12 differed depending on the culture medium, and hypoxic conditions did not increase hybrid myotubes' formation (Figure 2D, F). 
The changes in expression of selected markers in human and pig bone marrow-derived MSCs and mouse primary myoblasts under normoxic and hypoxic conditions

To follow the changes in myogenic differentiation of cells cultured under normoxic and hypoxic conditions in two different types of media (MSCmed and PMmed), the expression of transcript encoding PAX7, myogenic regulatory factors (MRFs), cytoskeletal proteins, and adhesion proteins was examined in mouse, human and pig cells (Figure 3). The expression of mouse Pax7, Myf5, Myod1, and myogenin (Myog) significantly increased in mPM cultured under hypoxic conditions, regardless of the culture medium used (Figure 3A). The higher level of mRNAs encoding Pax7 and MRFs in cells cultured under hypoxic conditions corresponded to myoblasts' higher proliferation. It is well known that Pax7, Myod1, and Myf5 are expressed in activated satellite cells, and Myod1 and Myf5 in proliferating cells (29). The expression of MRFs in hMSCs and pMSCs was barely detectable (Figure 3B, C). Human MYF5, MYOD1, and MYOG level increased in hMSCs cultured under hypoxic conditions but was still very low (Figure 3B).

The level of mRNAs encoding adhesion proteins, such as VCAM, NCAM, CD9, ADAM9, and mcadherin (cdh15 or CDH15) which are engaged in cell-cell adhesion and myoblast fusion (79-86) depended on the cell type and culture conditions used, i.e., medium and oxygen level (Figure 3A, B). Their expression was significantly higher in MPM cultured in PMmed than in MSCmed under normoxic. Moreover, we observed a significant decrease in $\mathrm{Cd} 9$ expression in MPM cultured under hypoxic conditions, regardless of medium type (Figure 3A). It corresponds to less efficient fusion of myoblasts observed under hypoxic conditions (Figure 2A). Analysis of hMSCs documented a significant decrease in ADAM9, CDH15, and CD9 expression levels when cells were cultured under hypoxic conditions, regardless of the medium used. In the case of pMSCs, the level of $\alpha$-sarcoglycan (SGCA) and desmin (DES) transcripts, i.e., encoding proteins characteristic for muscle cells $(87,88)$, changed dependently on culture conditions, being the highest in cells cultured in PMmed under hypoxic conditions (Figure 3C).

Co-culture of hMSCs or pMSCs cells with mPMs or $\mathrm{C} 2 \mathrm{C} 12$ myoblasts were analyzed to establish the changes in the expression of transcripts encoding MRFs, cytoskeletal, and adhesion proteins in human and pig cells cultured in the presence of myoblasts, under both normoxic or hypoxic conditions (Figure 4). Hypoxic increased hybrid myotube formation in co-cultures between either hMSCs or pMSCs and mPMs, in comparison to co-cultures conducted under normoxic. The level of human MRFs was significantly higher in hMSCs co-cultured with mPM than hMSCs cultured alone under all culture conditions tested (Figure 3B and $4 \mathrm{~A}$ ). Thus, the presence of myoblasts impacted the MRF expression in hMSCs. Moreover, we detected a higher expression level of human MYF5 and MYOD1 in co-cultures with mouse myoblasts carried in PMmed under normoxic conditions and in both types of the medium 
under hypoxic conditions (Figure 4A). Also, the level of transcripts encoding human CD9 and CDH15 significantly increased in cells cultured under hypoxic conditions. Hypoxic and myoblasts' presence did not alter the MYOG expression in pMSCs, but the high level of DES (desmin) was noticed in cells cultured in MSCmed (Figure 4B).

The transplantation of human bone marrow-derived MSCS cultured under normoxic and hypoxic conditions into mouse injured skeletal muscles

As we demonstrated, human and pig bone marrow-derived MSCs influenced myoblasts' proliferation and fusion when cultured under hypoxic conditions. Since any significant differences between human and pig cells' impact on mouse myoblasts were found, we decided to inject human bone marrow-derived MSCs into injured mouse muscle. Before transplantation, we examined the expression of human progenitor cell (MCAM/CD146), pericyte (PDGFRb, NG2), endothelial (VEGFR), and fibroblast (FAP) markers in hMSCs cultured in MSCmed under normoxic and hypoxic conditions (Figure 5). CD146 was shown to be a marker of a subpopulation of human bone marrow-derived stem cells [88, 89]. We noticed that the expression of MCAM/CD146 and NG2 (CSPG4) increased under hypoxic conditions. However, the expression of FAP also increased. The level of PDGFRb and KDR (VEGFR) did not change significantly under hypoxic conditions. Then we analyzed the level of transcripts of secreted proteins engaged in cell mobilization and differentiation, such as SDF-1 (CXCL12), VEGF, VWF, and WNT4. We found that the level of VEGF increased in hMSCs cultured under hypoxic conditions.

Finally, hMSC cultured under normoxic conditions and hypoxic preconditioned hMSCs were transplanted into ctx injured skeletal muscle of SCID mice (Figure 6). The muscle mass, nerve area, and a number of newly formed myofibers did not differ between muscles that received hMSCs cultured under either normoxic or hypoxic conditions (Figure 6A, B). Importantly, the area of blood vessels was higher after hypoxic preconditioned hMSC transplantation. Moreover, a higher number of human cells was detected in mouse muscles injected with hypoxic preconditioned hMSCs (Figure 6A, C). These cells were found between myofibers (Figure $6 \mathrm{C}$ ). However, the higer area of connective tissue in muscles injected with hMSCs cultured under hypoxic conditions compering to control muscles was noticed (Figure 6A). Then, we analyzed the level of mouse and human transcripts after cell transplantation. The level of mouse Vwf was lower in injured muscles than in intact muscle; however, it did not differ between muscles transplanted with hMSC cultured under either standard or hypoxic conditions (Figure 6D). Notably, only in mouse muscles injected with hypoxic preconditioned hMSCs the human transcripts such as laminin, VCAM, MCAM, PDGFRb, CSPG4 (NG2), FAP, CXCL12 (SDF-1), and VEGF were found (Figure 6E). Besides, the WNT, MYH3, MYF5, MYOD1, and MYOG transcripts were not detected. We 
concluded that hypoxic preconditioned hMSCs efficiently engrafted injured muscle but did not follow myogenic differentiation based on obtained results.

\section{Discussion}

Under physiological conditions, the oxygen level in healthy resting human skeletal muscles equates from $3 \%$ to $4 \%$ (25-34 mmHg) (89). Moreover, during intense exercise, human skeletal muscle oxygenation decreases to $7.5 \mathrm{mmHg} \mathrm{O}_{2}$ (90). In resting mouse muscle, the oxygenation reaches approximately $50 \mathrm{mmHg} \mathrm{O}_{2}$ (90). All these values are significantly lower than oxygen pressure under standard cell culture, amounting to circa $142 \mathrm{mmHg}$ (i.e., approx. 20\% O2), thus being higher (hyperoxic) to cells than oxygen pressure in vivo. For this reason, cell cultures performed under hypoxic conditions (oxygen pressure below $50 \mathrm{mmHg}, 2-6 \% \mathrm{O}_{2}$ ) are considered more physiological for bone marrow and muscle cells $(90,91)$. The level of oxygen influences many cellular processes regulating the activity of $\mathrm{O}_{2}$-consuming enzymes such as cytochrome c oxidase, stearoyl-CoA desaturase, NADPH oxidases, prolyl hydroxylase, as well as influencing on ROS formation (90-93). One of the essential proteins responsible for cell reaction to $\mathrm{O} 2$ level changes is hypoxic-inducible factor 1 (HIF-1), which regulates hypoxic responsive genes (94). The $\mathrm{O}_{2}$ level impacts inter alia, cell proliferation, migration, differentiation, viability, protein synthesis, and secretion (90).

In our study, we noticed an increase of primary myoblast proliferation when cultured under hypoxic conditions, which stays in agreement with other studies showing the higher proliferation of rat, human, and mouse primary myoblasts cultured in hypoxic $\left(2-6 \% \mathrm{O}_{2}\right)(95-98)$. The $\mathrm{C} 2 \mathrm{C} 12$ proliferation also increased in co-cultures with mouse bone marrow-derived MSCs in VEGF dependent manner (99). Importantly, under hypoxic conditions, we observed the increased VEGF expression in human bone marrow-derived MSCs. However, neither human nor pig bone marrow-derived MSC proliferation or migration changed when comparing the cells cultured under normoxic or hypoxic conditions. Although no significant influence of hypoxic on rat bone marrow-derived MSC migration was found, it was shown that the oxygen concentration affected bone marrow-derived MSC response to chemokines, inflammatory cytokines, and growth factors (100). On the other hand, mouse bone marrow-derived MSCs migrated more efficiently, in transmembrane migration assay, in response to conditioned medium under hypoxic conditions (68). Human bone marrow-derived MSCs cultured under hypoxic conditions increased their migration rates and HGF receptor expression, i.e., c-Met (101). Thus, the influence of hypoxic on bone marrow-derived MSC migration abilities depends on many variables.

In the current study, we documented that primary myoblasts and C2C12 myoblasts fused less efficiently under hypoxic conditions. Other studies showed that the impaired fusion of mouse $\mathrm{C} 2 \mathrm{C} 12$ 
myoblasts cultured under hypoxic conditions was also connected to myotube atrophy and a lower number of nuclei per myotube (102). Also, mouse primary and H-2K myoblast differentiation were less efficient under such conditions (103). Moreover, most of the studies described the inhibition of myogenic differentiation under hypoxic (91). The response of mouse satellite cells to oxygen level changes is regulated by HIF2A (89). Quiescent satellite cells residing within the niche are hypoxic and express HIF2A, which maintains their quiescence and self-renewal and blocks differentiation (89). We noticed that the expression of Pax7 and MRFs, i.e., MyoD, Myf5, and Myog, increased in myoblasts under hypoxic conditions. The higher level of Pax7 and MRF expression could be connected with the elevated proliferation of myoblasts in hypoxic. Moreover, hypoxic culture conditions were shown to activate Notch1, leading to a reduction in miR1 and miR206 expression and PAX7 upregulation (104). The observed decrease in primary myoblast fusion corresponds to the lower expression level of tetraspanin Cd9 in cells under hypoxic conditions, independent of culture medium. CD9 protein is engaged in myoblast fusion. Thus, its lower level could be connected with impaired fusion $(82,83,105$, 106).

Interestingly, we noticed that fusion of myoblasts changed in the presence or absence of bone marrow-derived MSCs. As long as the bone marrow-derived MSCs and myoblasts were co-cultured under standard culture conditions, the fusion did not change significantly comparing to myoblast cultures. Under hypoxic conditions, the presence of human or pig bone marrow-derived MSCS significantly improved myoblast fusion, i.e., enhanced myoblast differentiation. Simultaneously, the higher number of hybrid myotubes formed by mouse primary myoblasts and either human or pig bone marrow-derived MSCs were observed under hypoxic conditions. To find the mechanism determining such phenomenon, we examined the changes in human or pig MRFs' expression level, adhesion proteins, cytoskeletal proteins, and other myoblast markers, such as dystrophin or sarcoglycan, in bone marrow-derived MSCs and co-cultures of bone marrow-derived MSCs and myoblasts. The level of human or pig MRF mRNAs was very low or undetectable. It, however, increased under hypoxic conditions but only in human bone marrow-derived MSCs. The expression level of adhesion proteins engaged in cell fusion varied depending on cell culture medium and conditions. Then, we analyzed the level of secreted factors transcripts, such as SDF-1, VEGF-1, WNT4, and VWF, and found that under hypoxic conditions, expression of VEGF significantly increased in human bone marrow-derived MSCs. It was also documented that mouse bone marrow-derived MSCs overexpressed Vegf and secreted a higher VEGF level under hypoxic conditions $(67,68)$. Moreover, both mouse primary myoblasts and C2C12 myoblasts expressed VEGF and its receptors (107). VEGF enhanced C2C12 myoblast migration and prevented apoptosis (107) and myogenic differentiation, which resulted in the promotion of myotube hypertrophy of $\mathrm{C} 2 \mathrm{C} 12$ cells, increased mitogenic activity, migration, and proliferation (99, 
108). Thus, we concluded that an increase of VEGF secretion by bone marrow-derived MSCs, observed under hypoxic conditions, could account for improved myoblast proliferation and differentiation.

Finally, we transplanted hypoxic preconditioned human bone marrow-derived MSCs to injured skeletal muscles of SCID mice to study their influence on tissue regeneration. Bone marrow-derived MSCs cultured under hypoxic more efficiently engrafted the muscle. However, they were found only between myofibers. We were able to detect human lamina, VCAM, NG2, CD146, PDGFR, and FAP in muscles after hypoxic preconditioned bone marrow-derived MSC transplantation with more effective engraftment. However, we did not notice the presence of myofibers formed by human bone marrowderived MSCs, and the expression of human MYF5, MYOD, MYOG, and MYH3 was not detected. Thus, we concluded that hypoxic preconditioned bone marrow-derived MSCs more efficiently engrafted injured muscles but did not follow myogenic differentiation. Notably, the human SDF-1 and VEGF transcripts were present in mouse muscle after hypoxic preconditioned bone marrow-derived MSC transplantation, and these factors could impact skeletal muscle regeneration. We suggested that VEGF, which is upregulated in hypoxic preconditioned bone marrow-derived MSCs, could play a vital role in cell engraftment after transplantation. Verma and coworkers showed that tissue-resident satellite cells expressed VEGF, which recruited endothelial cells (109). In this way, satellite cells induced capillary formation in their niche. We suggested that improved expression of VEGF in hypoxic preconditioned bone marrow-derived MSCs could induce vessel formation and support cell engraftment. A higher number of vessels was found in muscles after hypoxic preconditioned bone marrow-derived MSC transplantation. Reconstruction of vessel network is essential for muscle reconstruction, and the reduction of skeletal muscle network was described in dystrophic, ALS, or denervated muscles (110). Acute muscle damage led to disruption in the microvasculature, hypoxic, and activation of HIF-1 $\alpha$ signaling - the main factor of hypoxic response (111). One of the HIF-1 target genes is VEGF, i.e., a welldescribed factor triggering angiogenesis also in skeletal muscles (111). VEGF and angiogenesis improved skeletal muscle regeneration and chronic skeletal muscle diseases (108, 111-113). Similarly, SDF-1 expression increased in injured muscles, presented a proangiogenic effect, and mobilized stem cells to injured muscles (114-118). The restoration of blood flow and vascular formation was also enhanced after intra-arterial injection of hypoxic preconditioned mouse bone marrow-derived MSCs to mice with hind limb ischemia (101). Hypoxic preconditioned mouse bone marrow-derived MSC transplantation increased WNT4 expression in skeletal muscles, and WNT4 was shown to induce bone marrow-derived MSC proliferation and migration well as endothelial cell migration and myoblast differentiation (101). Based on all the abovementioned results, we concluded that SDF-1 and VEGF secreted by hypoxic preconditioned bone marrow-derived MSCs increased new vessel formation during skeletal muscle reconstruction. 


\section{Conclusions}

The hypoxic induced proliferation of myoblasts but delayed their differentiation, decreased transcripts encoding CD9, and increased PAX7 and MRFs transcripts expression. The bone marrow-derived MSCs significantly improved myoblast proliferation and differentiation in co-cultures under hypoxic conditions in vitro in VEGF dependent manner. Moreover, bone marrow-derived MSCs are more frequently fused in vitro with myoblasts under hypoxic conditions. Hypoxic preconditioning of bone marrow-derived MSCs increased the level of VEGF expression. Hypoxic preconditioned bone marrow-derived MSCs more efficiently engrafted injured muscles in vivo but did not follow myogenic differentiation. Transplantation of hypoxic preconditioned bone marrow-derived MSCs into injured muscles increased muscle mass and new vessels' formation in SDF-1 and VEGF dependent manner.

Ethics approval and consent to participate: Local Ethics Committee No. 1 in Warsaw, Poland, approved all procedures involving animals - permission number: 669/2018.

Consent for publication: All authors have read and agreed to the published version of the manuscript.

Availability of data and materials: The datasets used and/or analysed during the current study are available from the corresponding author on reasonable request.

Acknowledgements: Part of the study was carried out with the infrastructure of Center for Preclinical Research, Medical University of Warsaw, Warsaw, Poland infrastructure, financed by the European Union through the European Regional Development Fund within operational program Innovative Economy for 2007-2013.

\section{Author s' contributions}

Conceptualization, MJ and EB; Methodology, EB; KA and IG; Investigation, BM; JG; AG; MK; AMR; IK; WS; $\mathrm{KJI}$ and PW; Data Curation, EB; BM; KA; IG; Writing-Original Draft Preparation, EB; BM; KA; IG; Writing-Review and Editing, EB; BM; KA; IG; MAC; MJ and PW; Visualization, IG and KA; Supervision, EB; MAC and MJ; Project Administration, WS; Funding Acquisition, MJ.

Funding: This research received funding from National Centre for Research and Development, grant number: STRATEGMED1/235773/19/NCBR/2016.

Competing interests: The authors declare they have no competing interest. $\mathrm{MJ}$ and $\mathrm{PW}$ are co-founders and co-owners of Ti-com, LLC, and IntraART, LLC, which are not directly related to the current manuscript.

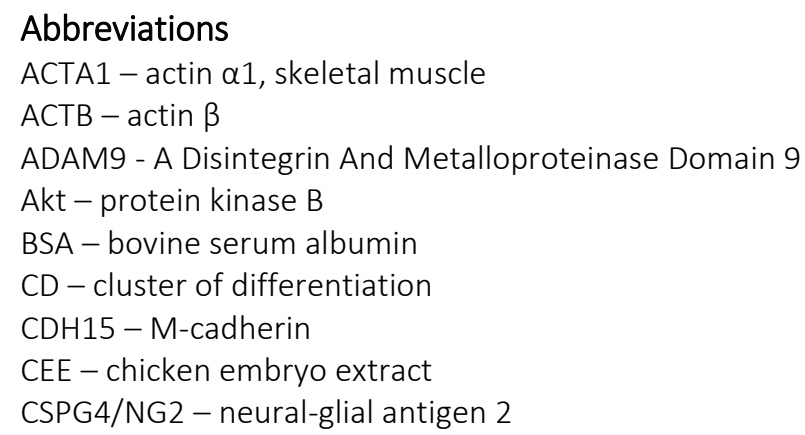


CXCL12/SDF1 - C-X-C chemokine 12/stromal derived factor 1

DAMP - damage-associated molecular pattern

DES - desmin

DMEM - Dulbecco's modified Eagle's medium

ECM - extracellular matrix

EDL - extensor digitorum longus

FAP - fibroblast activation protein

FBSin - fetal bovine serum inactivated

FDB - flexor digitorum brevis

FGF - fibroblast growth factor

FOXO - forkhead box $\mathrm{O}$

GFP - green fluorescent protein

HGF - hepatocyte growth factor

HGFR/c-Met - hepatocyte growth factor receptor

HIF - hypoxic-inducible factor

hMSC - human mesenchymal stem/stromal cell

HPRT - Hypoxanthine phosphoribosyltransferase

HS - horse serum

IGF-1 - insulin - like growth factor 1

$\mathrm{IL}$ - interleukin

KDR/VEGFR - vascular endothelial growth factor receptor

MAPK - mitogen-activated protein kinase

MCAM/CD146 - melanoma cell adhesion molecule

MMP - metalloproteinase

mPM - mouse primary myoblasts

MRF - myogenic regulatory factor

MRF4 - myogenic regulatory factor 4

MSC - mesenchymal stem/stromal cell

MSCmed - mesenchymal stromal cells medium

mTOR - mammalian target of rapamycin

MYF5 - myogenic factor 5

MYH3 - Myosin heavy chain 3, embryonic

MYOD - myoblast determination protein

MYOG - myogenin

NADPH - Nicotinamide adenine dinucleotide phosphate (reduced)

NCAM1 - neural cell adhesion molecule 1

NES - nestin

NFATc - nucelar factor of activated T-cells, cytoplasmic

NF-kB - nuclear factor kappa B

NICD - Notch intracellular domain

$\mathrm{NO}$ - nitric oxide

Pax3 - paired box transcription factor 3

Pax7 - paired box transcription factor 7

PBS - phosphate buffer saline

PDFGRB - Platelet-derived growth factor receptor $\beta$

PFA - paraformaldehyde

PI3K - phosphoinositide 3-kinase

PMmed - primary myoblasts medium

pMSC - pig mesenchymal stem/stromal cell

ROS - reactive oxygen species

$\mathrm{SC}$ - satellite cell

SCID - severe combined immunodeficiency

SGCA - $\alpha$ sarcoglycan

STAT3 - signal transducer and activator of transcription 3

TA - tibialis anterior

TGF- $\beta$ - tumor growth factor $\beta$

TNF- $\alpha$ - tumor necrosis factor $\alpha$ 
TRPC - transient receptor potential cation channel

VCAM - vascular cell adhesion molecule

VEGF - vascular endothelial growth factor

VWF - von Willebrand factor

WNT - wingless/integrated 


\section{Bibliography}

1. Charge SB, Rudnicki MA. Cellular and molecular regulation of muscle regeneration. Physiol Rev. 2004;84(1):209-38.

2. Yang $\mathrm{Y}$, Jiang $\mathrm{G}$, Zhang $\mathrm{P}$, Fan J. Programmed cell death and its role in inflammation. Military Medical Research. 2015;2:12. Epub 2015/06/06.

3. Roh JS, Sohn DH. Damage-Associated Molecular Patterns in Inflammatory Diseases. Immune network. 2018;18(4):e27. Epub 2018/09/06.

4. Tidball JG, Villalta SA. Regulatory interactions between muscle and the immune system during muscle regeneration. Am J Physiol Regul Integr Comp Physiol. 2010;298(5):R1173-87. Epub 2010/03/12.

5. Tidball JG. Inflammatory processes in muscle injury and repair. Am J Physiol Regul Integr Comp Physiol. 2005;288(2):R345-53.

6. Pizza FX, Peterson JM, Baas JH, Koh TJ. Neutrophils contribute to muscle injury and impair its resolution after lengthening contractions in mice. J Physiol. 2005;562(Pt 3):899-913. Epub 2004/11/20.

7. Forcina L, Cosentino M, Musaro A. Mechanisms Regulating Muscle Regeneration: Insights into the Interrelated and Time-Dependent Phases of Tissue Healing. Cells. 2020;9(5). Epub 2020/05/28.

8. Silva MT. When two is better than one: macrophages and neutrophils work in concert in innate immunity as complementary and cooperative partners of a myeloid phagocyte system. J Leukoc Biol. 2010;87(1):93-106. Epub 2010/01/07.

9. Chazaud B. Macrophages: supportive cells for tissue repair and regeneration. Immunobiology. 2014;219(3):172-8. Epub 2013/10/02.

10. Chazaud B, Brigitte M, Yacoub-Youssef H, Arnold L, Gherardi R, Sonnet C, et al. Dual and beneficial roles of macrophages during skeletal muscle regeneration. Exerc Sport Sci Rev. 2009;37(1):18-22.

11. Mantovani A, Sica A, Locati M. New vistas on macrophage differentiation and activation. Eur J Immunol. 2007;37(1):14-6. Epub 2006/12/22.

12. Novak ML, Koh TJ. Macrophage phenotypes during tissue repair. J Leukoc Biol. 2013;93(6):87581. Epub 2013/03/19.

13. Rigamonti E, Zordan P, Sciorati C, Rovere-Querini P, Brunelli S. Macrophage plasticity in skeletal muscle repair. BioMed research international. 2014;2014:560629. Epub 2014/05/27.

14. Arnold L, Henry A, Poron F, Baba-Amer Y, van Rooijen N, Plonquet A, et al. Inflammatory monocytes recruited after skeletal muscle injury switch into antiinflammatory macrophages to support myogenesis. J Exp Med. 2007;204(5):1057-69. Epub 2007/05/09.

15. Villalta SA, Nguyen HX, Deng B, Gotoh T, Tidball JG. Shifts in macrophage phenotypes and macrophage competition for arginine metabolism affect the severity of muscle pathology in muscular dystrophy. Hum Mol Genet. 2009;18(3):482-96. Epub 2008/11/11.

16. Mauro A. Satellite cell of skeletal muscle fibers. J Biophys Biochem Cytol. 1961;9:493-5.

17. Relaix F, Zammit PS. Satellite cells are essential for skeletal muscle regeneration: the cell on the edge returns centre stage. Development. 2012;139(16):2845-56. Epub 2012/07/27.

18. Mierzejewski B, Archacka K, Grabowska I, Florkowska A, Ciemerych MA, Brzoska E. Human and mouse skeletal muscle stem and progenitor cells in health and disease. Semin Cell Dev Biol. 2020;104:93-104. Epub 2020/02/02.

19. Brzoska E, Ciemerych MA, Przewozniak M, Zimowska M. Regulation of muscle stem cells activation: the role of growth factors and extracellular matrix. Vitam Horm. 2011;87:239-76. Epub 2011/12/01.

20. Chen X, Li Y. Role of matrix metalloproteinases in skeletal muscle: migration, differentiation, regeneration and fibrosis. Cell adhesion \& migration. 2009;3(4):337-41. Epub 2009/08/12.

21. DiMario J, Buffinger N, Yamada S, Strohman RC. Fibroblast growth factor in the extracellular matrix of dystrophic (mdx) mouse muscle. Science. 1989;244(4905):688-90. Epub 1989/05/12.

22. Liu Y, Schneider MF. FGF2 activates TRPC and $\mathrm{Ca}(2+)$ signaling leading to satellite cell activation. Frontiers in physiology. 2014;5:38. Epub 2014/02/28. 
23. Jones NC, Tyner KJ, Nibarger L, Stanley HM, Cornelison DD, Fedorov YV, et al. The p38alpha/beta MAPK functions as a molecular switch to activate the quiescent satellite cell. J Cell Biol. 2005;169(1):105-16. Epub 2005/04/13.

24. Allen RE, Sheehan SM, Taylor RG, Kendall TL, Rice GM. Hepatocyte growth factor activates quiescent skeletal muscle satellite cells in vitro. J Cell Physiol. 1995;165(2):307-12.

25. Machida S, Spangenburg EE, Booth FW. Forkhead transcription factor FoxO1 transduces insulin-like growth factor's signal to p27Kip1 in primary skeletal muscle satellite cells. J Cell Physiol. 2003;196(3):523-31. Epub 2003/08/02.

26. Acharyya S, Sharma SM, Cheng AS, Ladner KJ, He W, Kline W, et al. TNF inhibits Notch-1 in skeletal muscle cells by Ezh2 and DNA methylation mediated repression: implications in duchenne muscular dystrophy. PLoS One. 2010;5(8):e12479. Epub 2010/09/04.

27. Tatsumi R. Mechano-biology of skeletal muscle hypertrophy and regeneration: possible mechanism of stretch-induced activation of resident myogenic stem cells. Animal science journal = Nihon chikusan Gakkaiho. 2010;81(1):11-20. Epub 2010/02/19.

28. Serrano AL, Baeza-Raja B, Perdiguero E, Jardi M, Munoz-Canoves P. Interleukin- 6 is an essential regulator of satellite cell-mediated skeletal muscle hypertrophy. Cell metabolism. 2008;7(1):33-44. Epub 2008/01/08.

29. Zammit PS. Function of the myogenic regulatory factors Myf5, MyoD, Myogenin and MRF4 in skeletal muscle, satellite cells and regenerative myogenesis. Semin Cell Dev Biol. 2017;72:19-32. Epub 2017/11/12.

30. Pownall ME, Gustafsson MK, Emerson CP, Jr. Myogenic regulatory factors and the specification of muscle progenitors in vertebrate embryos. Annu Rev Cell Dev Biol. 2002;18:747-83. Epub 2002/07/27.

31. Halevy O, Novitch BG, Spicer DB, Skapek SX, Rhee J, Hannon GJ, et al. Correlation of terminal cell cycle arrest of skeletal muscle with induction of p21 by MyoD. Science. 1995;267(5200):1018-21. Epub 1995/02/17.

32. Hollenberg SM, Cheng PF, Weintraub H. Use of a conditional MyoD transcription factor in studies of MyoD trans-activation and muscle determination. Proc Natl Acad Sci U S A. 1993;90(17):8028-32. Epub 1993/09/01.

33. Davie JK, Cho JH, Meadows E, Flynn JM, Knapp JR, Klein WH. Target gene selectivity of the myogenic basic helix-loop-helix transcription factor myogenin in embryonic muscle. Dev Biol. 2007;311(2):650-64. Epub 2007/10/02.

34. Olguin HC, Yang Z, Tapscott SJ, Olwin BB. Reciprocal inhibition between Pax7 and muscle regulatory factors modulates myogenic cell fate determination. The Journal of Cell Biology. 2007;177(5):769-79. Epub 2007/06/06.

35. Olguin HC, Olwin BB. Pax-7 up-regulation inhibits myogenesis and cell cycle progression in satellite cells: a potential mechanism for self-renewal. Dev Biol. 2004;275(2):375-88.

36. Zammit PS, Carvajal JJ, Golding JP, Morgan JE, Summerbell D, Zolnerciks J, et al. Myf5 expression in satellite cells and spindles in adult muscle is controlled by separate genetic elements. Dev Biol. 2004;273(2):454-65.

37. Abmayr SM, Pavlath GK. Myoblast fusion: lessons from flies and mice. Development. 2012;139(4):641-56. Epub 2012/01/26.

38. Chal J, Pourquie O. Making muscle: skeletal myogenesis in vivo and in vitro. Development. 2017;144(12):2104-22. Epub 2017/06/22.

39. Gayraud-Morel B, Chretien F, Tajbakhsh S. Skeletal muscle as a paradigm for regenerative biology and medicine. Regenerative medicine. 2009;4(2):293-319. Epub 2009/03/26.

40. Bloch-Gallego E. Mechanisms controlling neuromuscular junction stability. Cell Mol Life Sci. 2015;72(6):1029-43. Epub 2014/11/02.

41. Dumont NA, Bentzinger CF, Sincennes MC, Rudnicki MA. Satellite Cells and Skeletal Muscle Regeneration. Comprehensive Physiology. 2015;5(3):1027-59. Epub 2015/07/04. 
42. Archacka K, Brzoska E, Ciemerych MA, Czerwinska AM, Grabowska I, Kowalski K, et al. Pluripotent and Mesenchymal Stem Cells-Challenging Sources for Derivation of Myoblast. In: Brzozka Z, Jastrzebska E, editors. Cardiac Cell Culture Technologies,2018.

43. Elsafadi M, Manikandan M, Atteya M, Hashmi JA, Iqbal Z, Aldahmash A, et al. Characterization of Cellular and Molecular Heterogeneity of Bone Marrow Stromal Cells. Stem cells international. 2016;2016:9378081. Epub 2016/09/10.

44. Robey PG, Kuznetsov SA, Bianco P, Riminucci M. Bone Marrow Stromal Cell Assays: In Vitro and In Vivo. Methods Mol Biol. 2021;2230:379-96. Epub 2020/11/17.

45. Sacchetti B, Funari A, Remoli C, Giannicola G, Kogler G, Liedtke S, et al. No Identical "Mesenchymal Stem Cells" at Different Times and Sites: Human Committed Progenitors of Distinct Origin and Differentiation Potential Are Incorporated as Adventitial Cells in Microvessels. Stem cell reports. 2016;6(6):897-913. Epub 2016/06/16.

46. Bianco P. Stem cells and bone: a historical perspective. Bone. 2015;70:2-9. Epub 2014/08/31.

47. Bianco P. "Mesenchymal" stem cells. Annu Rev Cell Dev Biol. 2014;30:677-704. Epub 2014/08/26.

48. Bianco P, Cao X, Frenette PS, Mao JJ, Robey PG, Simmons PJ, et al. The meaning, the sense and the significance: translating the science of mesenchymal stem cells into medicine. Nat Med. 2013;19(1):35-42. Epub 2013/01/09.

49. Serafini M, Sacchetti B, Pievani A, Redaelli D, Remoli C, Biondi A, et al. Establishment of bone marrow and hematopoietic niches in vivo by reversion of chondrocyte differentiation of human bone marrow stromal cells. Stem Cell Res. 2014;12(3):659-72. Epub 2014/03/29.

50. Shi D, Reinecke H, Murry CE, Torok-Storb B. Myogenic fusion of human bone marrow stromal cells, but not hematopoietic cells. Blood. 2004;104(1):290-4. Epub 2004/03/11.

51. Kasprzycka P, Archacka K, Kowalski K, Mierzejewski B, Zimowska M, Grabowska I, et al. The factors present in regenerating muscles impact bone marrow-derived mesenchymal stromal/stem cell fusion with myoblasts. Stem cell research \& therapy. 2019;10(1):343. Epub 2019/11/23.

52. Kowalski K, Dos Santos M, Maire P, Ciemerych MA, Brzoska E. Induction of bone marrowderived cells myogenic identity by their interactions with the satellite cell niche. Stem cell research \& therapy. 2018;9(1):258. Epub 2018/09/29.

53. Cai A, Hardt M, Schneider P, Schmid R, Lange C, Dippold D, et al. Myogenic differentiation of primary myoblasts and mesenchymal stromal cells under serum-free conditions on PCL-collagen Inanoscaffolds. BMC Biotechnol. 2018;18(1):75. Epub 2018/11/28.

54. Wakitani S, Saito T, Caplan Al. Myogenic cells derived from rat bone marrow mesenchymal stem cells exposed to 5-azacytidine. Muscle \& nerve. 1995;18(12):1417-26. Epub 1995/12/01.

55. Dezawa $M$, Ishikawa $H$, Itokazu $Y$, Yoshihara $T$, Hoshino $M$, Takeda $S$, et al. Bone marrow stromal cells generate muscle cells and repair muscle degeneration. Science. 2005;309(5732):314-7. Epub 2005/07/09.

56. Shang $\mathrm{Y}$, Zhang $\mathrm{C}$, Wang $\mathrm{S}$, Xiong $\mathrm{F}$, Zhao $\mathrm{C}$, Peng $\mathrm{F}$, et al. Activated beta-catenin induces myogenesis and inhibits adipogenesis in BM-derived mesenchymal stromal cells. Cytotherapy. 2007;9(7):667-81. Epub 2007/10/06.

57. Gang EJ, Darabi R, Bosnakovski D, Xu Z, Kamm KE, Kyba M, et al. Engraftment of mesenchymal stem cells into dystrophin-deficient mice is not accompanied by functional recovery. Exp Cell Res. 2009;315(15):2624-36. Epub 2009/05/23.

58. Gang EJ, Bosnakovski D, Simsek T, To K, Perlingeiro RC. Pax3 activation promotes the differentiation of mesenchymal stem cells toward the myogenic lineage. Experimental cell research. 2008;314(8):1721-33. Epub 2008/04/09.

59. Jiqing C, Yaqin L, Yingyin L, Fei C, Huili Z, Yuling Z, et al. BMP4 inhibits myogenic differentiation of bone marrow-derived mesenchymal stromal cells in mdx mice. Cytotherapy. 2015;17(9):1213-9. Epub 2015/08/16.

60. LaBarge MA, Blau HM. Biological progression from adult bone marrow to mononucleate muscle stem cell to multinucleate muscle fiber in response to injury. Cell. 2002;111(4):589-601. 
61. Brazelton TR, Nystrom M, Blau HM. Significant differences among skeletal muscles in the incorporation of bone marrow-derived cells. Dev Biol. 2003;262(1):64-74. Epub 2003/09/27.

62. Gussoni E, Soneoka Y, Strickland CD, Buzney EA, Khan MK, Flint AF, et al. Dystrophin expression in the $\mathrm{mdx}$ mouse restored by stem cell transplantation. Nature. 1999;401(6751):390-4.

63. Fukada S, Miyagoe-Suzuki Y, Tsukihara H, Yuasa K, Higuchi S, Ono S, et al. Muscle regeneration by reconstitution with bone marrow or fetal liver cells from green fluorescent protein-gene transgenic mice. J Cell Sci. 2002;115(Pt 6):1285-93. Epub 2002/03/09.

64. Palermo AT, Labarge MA, Doyonnas R, Pomerantz J, Blau HM. Bone marrow contribution to skeletal muscle: a physiological response to stress. Dev Biol. 2005;279(2):336-44. Epub 2005/03/01.

65. Grayson WL, Zhao F, Izadpanah R, Bunnell B, Ma T. Effects of hypoxia on human mesenchymal stem cell expansion and plasticity in 3D constructs. J Cell Physiol. 2006;207(2):331-9. Epub 2005/12/07. 66. Grayson WL, Zhao F, Bunnell B, Ma T. Hypoxia enhances proliferation and tissue formation of human mesenchymal stem cells. Biochem Biophys Res Commun. 2007;358(3):948-53. Epub 2007/05/25.

67. Potier E, Ferreira E, Andriamanalijaona R, Pujol JP, Oudina K, Logeart-Avramoglou D, et al. Hypoxia affects mesenchymal stromal cell osteogenic differentiation and angiogenic factor expression. Bone. 2007;40(4):1078-87. Epub 2007/02/06.

68. Annabi B, Lee YT, Turcotte S, Naud E, Desrosiers RR, Champagne M, et al. Hypoxia promotes murine bone-marrow-derived stromal cell migration and tube formation. Stem Cells. 2003;21(3):33747. Epub 2003/05/14.

69. Leroux L, Descamps B, Tojais NF, Seguy B, Oses P, Moreau C, et al. Hypoxia preconditioned mesenchymal stem cells improve vascular and skeletal muscle fiber regeneration after ischemia through a Wnt4-dependent pathway. Mol Ther. 2010;18(8):1545-52. Epub 2010/06/17.

70. Hu X, Yu SP, Fraser JL, Lu Z, Ogle ME, Wang JA, et al. Transplantation of hypoxia-preconditioned mesenchymal stem cells improves infarcted heart function via enhanced survival of implanted cells and angiogenesis. The Journal of thoracic and cardiovascular surgery. 2008;135(4):799-808. Epub 2008/04/01.

71. Nowakowski A, Walczak P, Lukomska B, Janowski M. Genetic Engineering of Mesenchymal Stem Cells to Induce Their Migration and Survival. Stem cells international. 2016;2016:4956063. Epub 2016/06/01.

72. Wei L, Fraser JL, Lu ZY, Hu X, Yu SP. Transplantation of hypoxia preconditioned bone marrow mesenchymal stem cells enhances angiogenesis and neurogenesis after cerebral ischemia in rats. Neurobiology of disease. 2012;46(3):635-45. Epub 2012/03/20.

73. Liu YY, Chiang $\mathrm{CH}$, Hung SC, Chian CF, Tsai CL, Chen WC, et al. Hypoxia-preconditioned mesenchymal stem cells ameliorate ischemia/reperfusion-induced lung injury. PLoS One. 2017;12(11):e0187637. Epub 2017/11/09.

74. Yu J, Yin S, Zhang W, Gao F, Liu Y, Chen Z, et al. Hypoxia preconditioned bone marrow mesenchymal stem cells promote liver regeneration in a rat massive hepatectomy model. Stem cell research \& therapy. 2013;4(4):83. Epub 2013/07/17.

75. Archacka K, Bem J, Brzoska E, Czerwinska AM, Grabowska I, Kasprzycka P, et al. Beneficial Effect of IL-4 and SDF-1 on Myogenic Potential of Mouse and Human Adipose Tissue-Derived Stromal Cells. Cells. 2020;9(6). Epub 2020/06/21.

76. Bischoff R. Proliferation of muscle satellite cells on intact myofibers in culture. Dev Biol. 1986;115(1):129-39. Epub 1986/05/01.

77. Rosenblatt JD, Lunt AI, Parry DJ, Partridge TA. Culturing satellite cells from living single muscle fiber explants. In Vitro Cell Dev Biol Anim. 1995;31(10):773-9.

78. Goetsch KP, Niesler CU. Optimization of the scratch assay for in vitro skeletal muscle wound healing analysis. Anal Biochem. 2011;411(1):158-60. Epub 2010/12/15.

79. Rosen GD, Sanes JR, LaChance R, Cunningham JM, Roman J, Dean DC. Roles for the integrin VLA-4 and its counter receptor VCAM-1 in myogenesis. Cell. 1992;69(7):1107-19. Epub 1992/06/26. 
80. Capkovic KL, Stevenson S, Johnson MC, Thelen JJ, Cornelison DD. Neural cell adhesion molecule (NCAM) marks adult myogenic cells committed to differentiation. Exp Cell Res. 2008;314(7):1553-65. Epub 2008/03/01.

81. Charlton CA, Mohler WA, Blau HM. Neural cell adhesion molecule (NCAM) and myoblast fusion. Dev Biol. 2000;221(1):112-9.

82. Charrin S, Latil M, Soave S, Polesskaya A, Chretien F, Boucheix C, et al. Normal muscle regeneration requires tight control of muscle cell fusion by tetraspanins CD9 and CD81. Nature communications. 2013;4:1674. Epub 2013/04/12.

83. Tachibana I, Hemler ME. Role of transmembrane 4 superfamily (TM4SF) proteins CD9 and CD81 in muscle cell fusion and myotube maintenance. J Cell Biol. 1999;146(4):893-904.

84. Yagami-Hiromasa T, Sato T, Kurisaki T, Kamijo K, Nabeshima Y, Fujisawa-Sehara A. A metalloprotease-disintegrin participating in myoblast fusion. Nature. 1995;377(6550):652-6. Epub 1995/10/19.

85. Kaufmann U, Kirsch J, Irintchev A, Wernig A, Starzinski-Powitz A. The M-cadherin catenin complex interacts with microtubules in skeletal muscle cells: implications for the fusion of myoblasts. J Cell Sci. 1999;112 ( Pt 1):55-68.

86. Przewozniak M, Czaplicka I, Czerwinska AM, Markowska-Zagrajek A, Moraczewski J, Streminska W, et al. Adhesion proteins--an impact on skeletal myoblast differentiation. PLoS One. 2013;8(5):e61760. Epub 2013/05/15.

87. Li Z, Mericskay M, Agbulut O, Butler-Browne G, Carlsson L, Thornell LE, et al. Desmin is essential for the tensile strength and integrity of myofibrils but not for myogenic commitment, differentiation, and fusion of skeletal muscle. J Cell Biol. 1997;139(1):129-44.

88. Cassano M, Dellavalle A, Tedesco FS, Quattrocelli M, Crippa S, Ronzoni F, et al. Alpha sarcoglycan is required for FGF-dependent myogenic progenitor cell proliferation in vitro and in vivo. Development. 2011;138(20):4523-33. Epub 2011/09/10.

89. Xie L, Yin A, Nichenko AS, Beedle AM, Call JA, Yin H. Transient HIF2A inhibition promotes satellite cell proliferation and muscle regeneration. J Clin Invest. 2018;128(6):2339-55. Epub 2018/03/14.

90. Ast T, Mootha VK. Oxygen and mammalian cell culture: are we repeating the experiment of Dr. Ox? Nature metabolism. 2019;1(9):858-60. Epub 2020/07/23.

91. Chaillou T, Lanner JT. Regulation of myogenesis and skeletal muscle regeneration: effects of oxygen levels on satellite cell activity. FASEB J. 2016;30(12):3929-41. Epub 2016/09/08.

92. Le Moal E, Pialoux V, Juban G, Groussard C, Zouhal H, Chazaud B, et al. Redox Control of Skeletal Muscle Regeneration. Antioxidants \& redox signaling. 2017;27(5):276-310. Epub 2016/12/29.

93. Hammarlund EU, Flashman E, Mohlin S, Licausi F. Oxygen-sensing mechanisms across eukaryotic kingdoms and their roles in complex multicellularity. Science. 2020;370(6515). Epub 2020/10/24.

94. Maltepe E, Saugstad OD. Oxygen in health and disease: regulation of oxygen homeostasis-clinical implications. Pediatr Res. 2009;65(3):261-8. Epub 2008/10/15.

95. Chakravarthy MV, Spangenburg EE, Booth FW. Culture in low levels of oxygen enhances in vitro proliferation potential of satellite cells from old skeletal muscles. Cell Mol Life Sci. 2001;58(8):1150-8. Epub 2001/09/01.

96. Csete M, Walikonis J, Slawny N, Wei Y, Korsnes S, Doyle JC, et al. Oxygen-mediated regulation of skeletal muscle satellite cell proliferation and adipogenesis in culture. J Cell Physiol. 2001;189(2):189-96. Epub 2001/10/13.

97. Urbani L, Piccoli M, Franzin C, Pozzobon M, De Coppi P. Hypoxia increases mouse satellite cell clone proliferation maintaining both in vitro and in vivo heterogeneity and myogenic potential. PLoS One. 2012;7(11):e49860. Epub 2012/11/21.

98. Koning M, Werker PM, van Luyn MJ, Harmsen MC. Hypoxia promotes proliferation of human myogenic satellite cells: a potential benefactor in tissue engineering of skeletal muscle. Tissue engineering Part A. 2011;17(13-14):1747-58. Epub 2011/03/29. 
99. Sassoli C, Pini A, Chellini F, Mazzanti B, Nistri S, Nosi D, et al. Bone marrow mesenchymal stromal cells stimulate skeletal myoblast proliferation through the paracrine release of VEGF. PLoS One. 2012;7(7):e37512. Epub 2012/07/21.

100. Naaldijk $Y$, Johnson AA, Ishak S, Meisel HJ, Hohaus C, Stolzing A. Migrational changes of mesenchymal stem cells in response to cytokines, growth factors, hypoxia, and aging. Exp Cell Res. 2015;338(1):97-104. Epub 2015/09/04.

101. Rosova I, Dao M, Capoccia B, Link D, Nolta JA. Hypoxic preconditioning results in increased motility and improved therapeutic potential of human mesenchymal stem cells. Stem Cells. 2008;26(8):2173-82. Epub 2008/05/31.

102. Bensaid S, Fabre C, Fourneau J, Cieniewski-Bernard C. Impact of different methods of induction of cellular hypoxia: focus on protein homeostasis signaling pathways and morphology of $\mathrm{C} 2 \mathrm{C} 12$ skeletal muscle cells differentiated into myotubes. Journal of physiology and biochemistry. 2019;75(3):367-77. Epub 2019/07/04.

103. Duguez S, Duddy WJ, Gnocchi V, Bowe J, Dadgar S, Partridge TA. Atmospheric oxygen tension slows myoblast proliferation via mitochondrial activation. PLoS One. 2012;7(8):e43853. Epub 2012/09/01.

104. Gustafsson MV, Zheng X, Pereira T, Gradin K, Jin S, Lundkvist J, et al. Hypoxia requires notch signaling to maintain the undifferentiated cell state. Dev Cell. 2005;9(5):617-28. Epub 2005/11/01.

105. Powner D, Kopp PM, Monkley SJ, Critchley DR, Berditchevski F. Tetraspanin CD9 in cell migration. Biochem Soc Trans. 2011;39(2):563-7. Epub 2011/03/25.

106. Charrin S, Le Naour F, Oualid M, Billard M, Faure G, Hanash SM, et al. The major CD9 and CD81 molecular partner. Identification and characterization of the complexes. J Biol Chem. 2001;276(17):14329-37.

107. Germani A, Di Carlo A, Mangoni A, Straino S, Giacinti C, Turrini P, et al. Vascular endothelial growth factor modulates skeletal myoblast function. Am J Pathol. 2003;163(4):1417-28. Epub 2003/09/26.

108. Bryan BA, Walshe TE, Mitchell DC, Havumaki JS, Saint-Geniez M, Maharaj AS, et al. Coordinated vascular endothelial growth factor expression and signaling during skeletal myogenic differentiation. Mol Biol Cell. 2008;19(3):994-1006. Epub 2007/12/21.

109. Verma M, Asakura Y, Murakonda BSR, Pengo T, Latroche C, Chazaud B, et al. Muscle Satellite Cell Cross-Talk with a Vascular Niche Maintains Quiescence via VEGF and Notch Signaling. Cell Stem Cell. 2018;23(4):530-43 e9. Epub 2018/10/06.

110. Valle-Tenney R, Rebolledo DL, Lipson KE, Brandan E. Role of hypoxia in skeletal muscle fibrosis: Synergism between hypoxia and TGF-beta signaling upregulates CCN2/CTGF expression specifically in muscle fibers. Matrix Biol. 2020;87:48-65. Epub 2019/11/02.

111. Valle-Tenney R, Rebolledo D, Acuna MJ, Brandan E. HIF-hypoxia signaling in skeletal muscle physiology and fibrosis. Journal of cell communication and signaling. 2020;14(2):147-58. Epub 2020/02/24.

112. Tang K, Breen EC, Gerber HP, Ferrara NM, Wagner PD. Capillary regression in vascular endothelial growth factor-deficient skeletal muscle. Physiological genomics. 2004;18(1):63-9. Epub 2004/04/16.

113. Arsic N, Zacchigna S, Zentilin L, Ramirez-Correa G, Pattarini L, Salvi A, et al. Vascular endothelial growth factor stimulates skeletal muscle regeneration in vivo. Mol Ther. 2004;10(5):844-54. Epub 2004/10/29.

114. Kowalski K, Kolodziejczyk A, Sikorska M, Placzkiewicz J, Cichosz P, Kowalewska M, et al. Stem cells migration during skeletal muscle regeneration - the role of Sdf-1/Cxcr4 and Sdf-1/Cxcr7 axis. Cell adhesion \& migration. 2017;11(4):384-98. Epub 2016/10/14.

115. Brzoska E, Kowalski K, Markowska-Zagrajek A, Kowalewska M, Archacki R, Plaskota I, et al. Sdf1 (CXCL12) induces CD9 expression in stem cells engaged in muscle regeneration. Stem cell research \& therapy. 2015;6:46. Epub 2015/04/19. 
116. Brzoska E, Kowalewska M, Markowska-Zagrajek A, Kowalski K, Archacka K, Zimowska M, et al. Sdf-1 (CXCL12) improves skeletal muscle regeneration via the mobilisation of Cxcr4 and CD34 expressing cells. Biol Cell. 2012;104(12):722-37. Epub 2012/09/18.

117. Kuliszewski MA, Kobulnik J, Lindner JR, Stewart DJ, Leong-Poi H. Vascular gene transfer of SDF1 promotes endothelial progenitor cell engraftment and enhances angiogenesis in ischemic muscle. Mol Ther. 2011;19(5):895-902. Epub 2011/03/03.

118. Ratajczak MZ, Majka M, Kucia M, Drukala J, Pietrzkowski Z, Peiper S, et al. Expression of functional CXCR4 by muscle satellite cells and secretion of SDF-1 by muscle-derived fibroblasts is associated with the presence of both muscle progenitors in bone marrow and hematopoietic stem/progenitor cells in muscles. Stem Cells. 2003;21(3):363-71. Epub 2003/05/14. 


\section{Figure legend}

Figure 1. Cell proliferation and migration under normoxic and hypoxic conditions. A - The number of mouse primary myoblasts (mPM), human bone marrow-derived mesenchymal stromal cells (hMSC), pig bone marrow-derived mesenchymal stromal cells (PMSC), cells in co-cultures of hMSC and MPM, and cells in co-cultures of pMSC and mPM, cultured in two types of medium: MSCmed and PMmed, under normoxic (NORM) or hypoxic (HYPO) conditions. B - the invaded area measured in scratch wound healing assay of hMSC and pMSC cultured in MSCmed under normoxic and hypoxic conditions. $\mathrm{C}-$ the scratch wound healing assay of hMSC and pMSC cultured in MSCmed under normoxic and hypoxic conditions. P-value: ${ }^{*}<0.05 ;{ }^{* *}<0.01 ;{ }^{* * *}<0.001 ; * * * * 0.0001$.

Figure 2. The fusion index and hybrid myotubes presence in either human bone marrow-derived mesenchymal stromal cells (hMSC) or pig bone marrow-derived mesenchymal stem cells (pMSC) coculture with myoblasts: mouse primary myoblasts (mPM) or C2C12 myoblasts. A - the fusion index of mPM and hMSC or pMSC co-cultured in MSCmed or PMmed under normoxic (NORM) or hypoxic (HYPO) conditions. $\mathrm{B}$ - the fusion index of $\mathrm{C} 2 \mathrm{C} 12$ myoblasts and hMSC or pMSC co-cultured in $3: 2.5 ; 3: 5 ; 3: 7.5$ ratio, in $\mathrm{C} 2 \mathrm{C} 12 \mathrm{med}$, under normoxic (NORM) or hypoxic (HYPO) conditions. C - the percentage of hybrid myotubes in $\mathrm{MPM}$ and hMSC or pMSC co-cultures in MSCmed or PMmed under normoxic (NORM) or hypoxic (HYPO) conditions. D - the immunolocalization of hybrid myotubes in mPM and hMSC cocultures, red - skeletal myosin, blue - cell nuclei, green human cell nuclei. E - the percentage of hybrid myotubes in $\mathrm{C} 2 \mathrm{C} 12$ and hMSC or pMSC co-cultures in $\mathrm{C} 2 \mathrm{C} 12$ med under normoxic (NORM) or hypoxic (HYPO) conditions. F - the immunolocalization of hybrid myotubes in $\mathrm{C} 2 \mathrm{C} 12$ and hMSC co-cultures, red - skeletal myosin, blue - cell nuclei, green human cell nuclei. P-value: ${ }^{*}<0.05 ;{ }^{* *}<0.01 ; * * *<0.001$; $* * * *<0.0001$.

Figure 3. The expression of selected markers in cell cultures. A - the level of transcripts encoding PAX7, MYF5, MYOD1, myogenin (MYOG), VCAM1, NCAM1, CD9, ADAM9, m-cadherin (CDH15) in mouse primary myoblasts (mPM) cultured in PMmed or MSCsmed under normoxic (NORM) or hypoxic (HYPO) conditions. B - the level of transcripts encoding MYF5, MYOD1, myogenin (MYOG), VCAM1, CD9, ADAM9, m-cadherin (CDH15), nestin (NES) in human bone marrow-derived mesenchymal stromal cells (hMSC) cultured in PMmed or MSCsmed under normoxic (NORM) or hypoxic (HYPO) conditions. C - the level of transcripts encoding myogenin (MYOG), $\alpha$-sarcoglycan (SGCA), desmin (DES), and actin $\alpha 1$ (ACTA1) in pig bone marrow-derived mesenchymal stem cells (pMSC) cultured in PMmed or MSCsmed under normoxic (NORM) or hypoxic (HYPO) conditions. P-value: ${ }^{*}<0.05 ;{ }^{* *}<0.01 ;{ }^{* * *}<0.001$; $* * * *<0.0001$. 
Figure 4. The expression of selected markers in cell co-cultures. A - the level of human transcripts encoding MYF5, MYOD1, myogenin (MYOG), VCAM1, CD9, ADAM9, m-cadherin (CDH15), nestin (NES) in co-cultures of mouse primary myoblasts (mPM) and human bone marrow-derived mesenchymal stromal cells (hMSC) in PMmed or MSCsmed under normoxic (NORM) or hypoxic (HYPO) conditions. B - the level of pig transcripts encoding myogenin (MYOG) SGCA, desmin (DES), and actin $\alpha 1$ (ACTA1) in mPM and pig bone marrow-derived mesenchymal stem cells (pMSC) co-cultured in PMmed or MSCsmed under normoxic (NORM) or hypoxic (HYPO) conditions. P-value: ${ }^{*}<0.05 ;{ }^{* *}<0.01$; $* * *<0.001 ; * * * *<0.0001$.

Figure 5. The level of selected markers expression in human bone marrow-derived mesenchymal stromal cells (hMSC) cultured in MSCsmed under normoxic (NORM) or hypoxic (HYPO) conditions. P value: ${ }^{*}<0.05 ;{ }^{* *}<0.01 ;{ }^{* * *}<0.001 ; * * * *<0.0001$

Figure 6. The skeletal muscle regeneration after human bone marrow mesenchymal stromal cells (hMSC) transplantation. The hMSCs were cultured under normoxic (NORM) or hypoxic (HYPO) conditions and injected into cardiotoxin (CTX) injured muscles. A - the skeletal muscle weight, the area of connective tissue, blood vessels, nerves, and frequency of new myofibers in intact muscles or muscles injured (CTX) and transplanted with hMSC cultured either under normoxic (NORM) or hypoxic (HYPO) conditions. B - histology of intact muscles or in muscles injured (CTX) and transplanted with hMSC cultured under normoxic (NORM) or hypoxic (HYPO) conditions. C - localization of transplanted cells (blue - nuclei, red - laminin, green - human nuclei) in intact muscles or muscles injured (CTX) and transplanted with hMSC cultured under normoxic (NORM) or hypoxic (HYPO) conditions. D - the expression of selected mouse transcripts in intact muscles or muscles injured (CTX) and transplanted with hMSC cultured under normoxic (NORM) or hypoxic (HYPO) conditions. E - the expression of selected human transcripts in intact muscles or muscles injured (CTX) and transplanted with hMSC cultured under normoxic (NORM) or hypoxic (HYPO) conditions. P-value: ${ }^{*}<0.05 ; * *<0.01 ; * * *<0.001$; $* * * *<0.0001$. 
Fig. 1

$\begin{array}{lllll}\text { A } \mathrm{mPM} & \mathrm{hMSC} & \mathrm{hMSC} / \mathrm{mPM} & \mathrm{pMSC} / \mathrm{mPM}\end{array}$

B
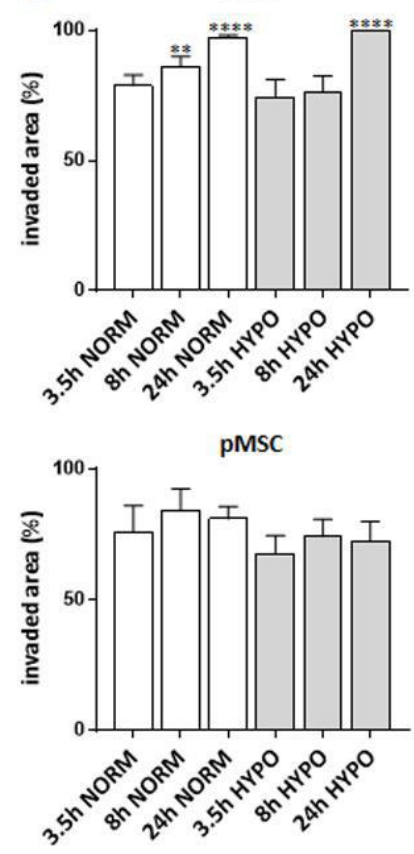

C
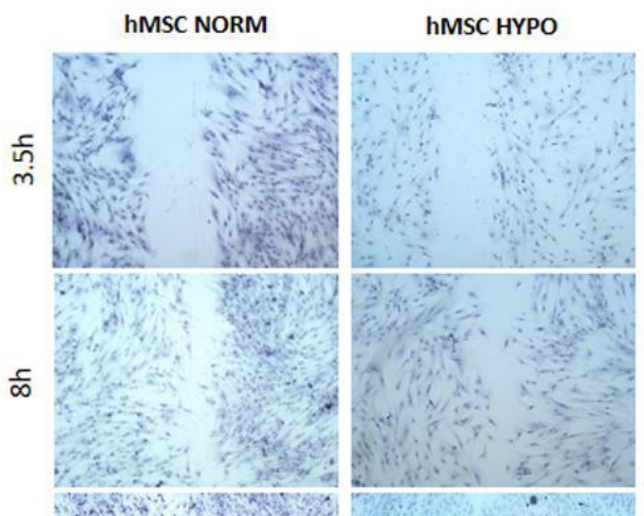

先
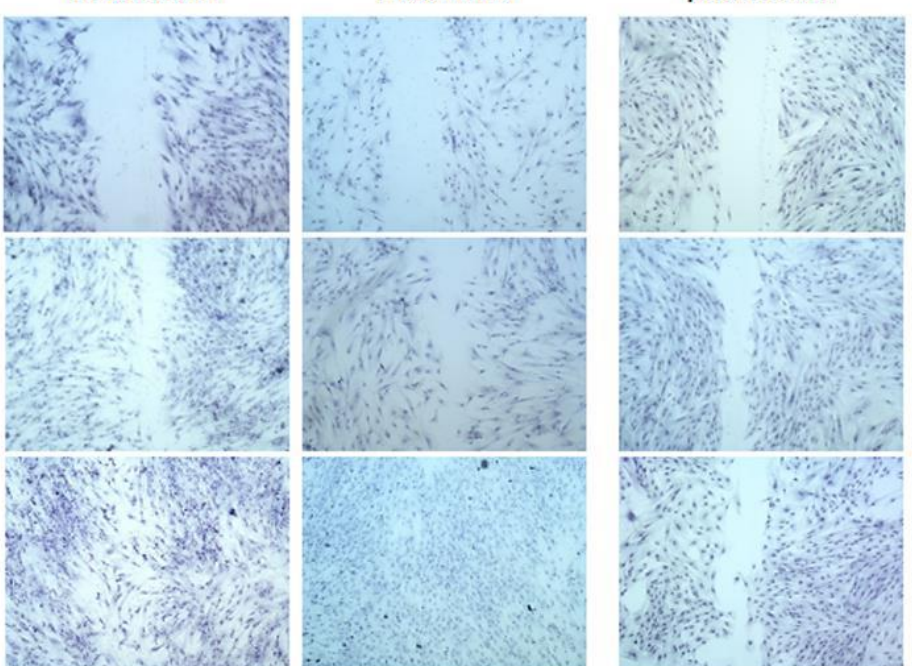

PMSC HYPO

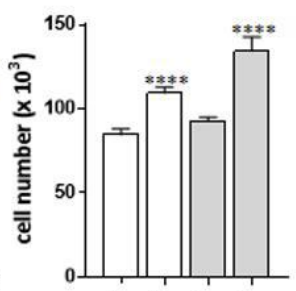

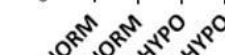

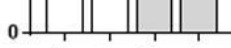

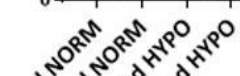

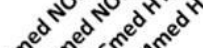

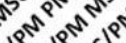


Fig. 2

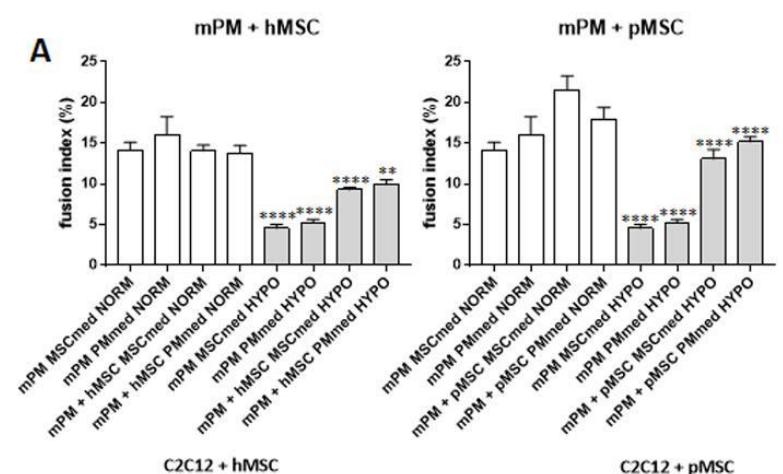

B
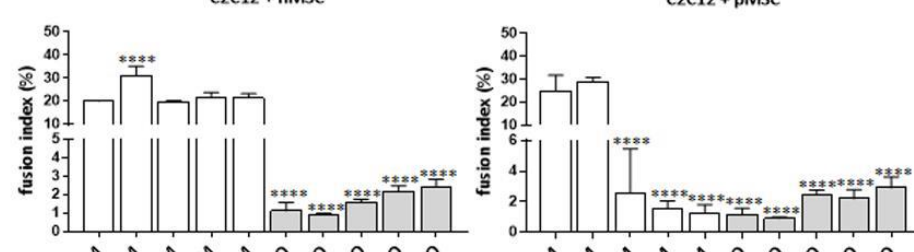

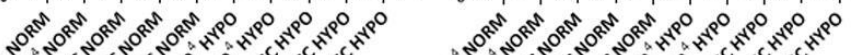
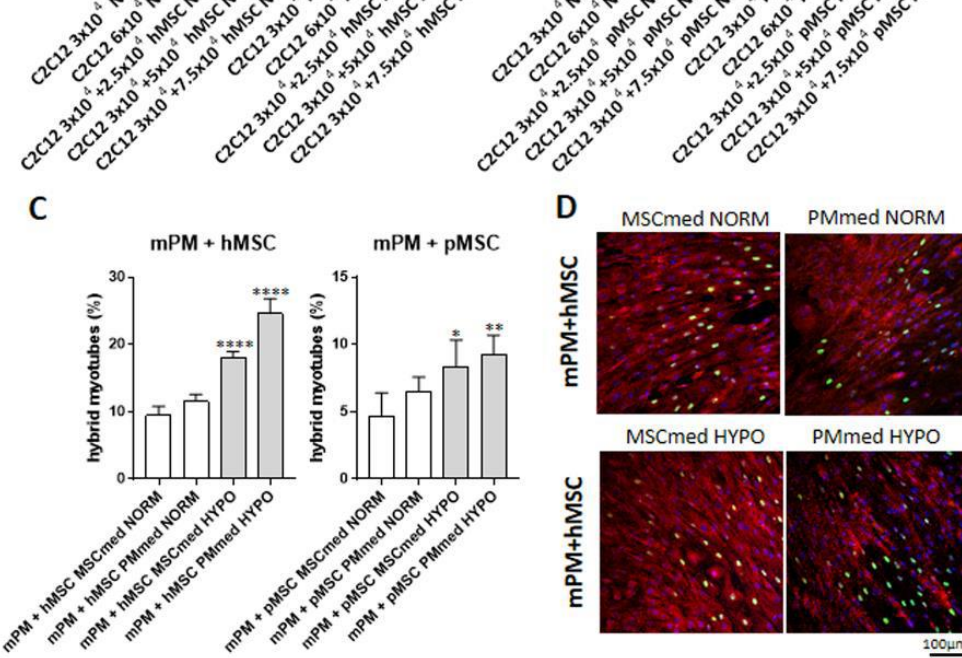

D MSCmed NORM PMmed NORM
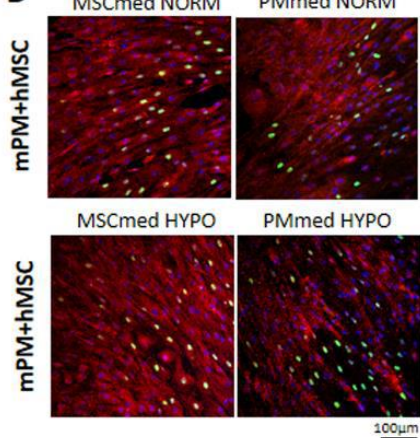

E
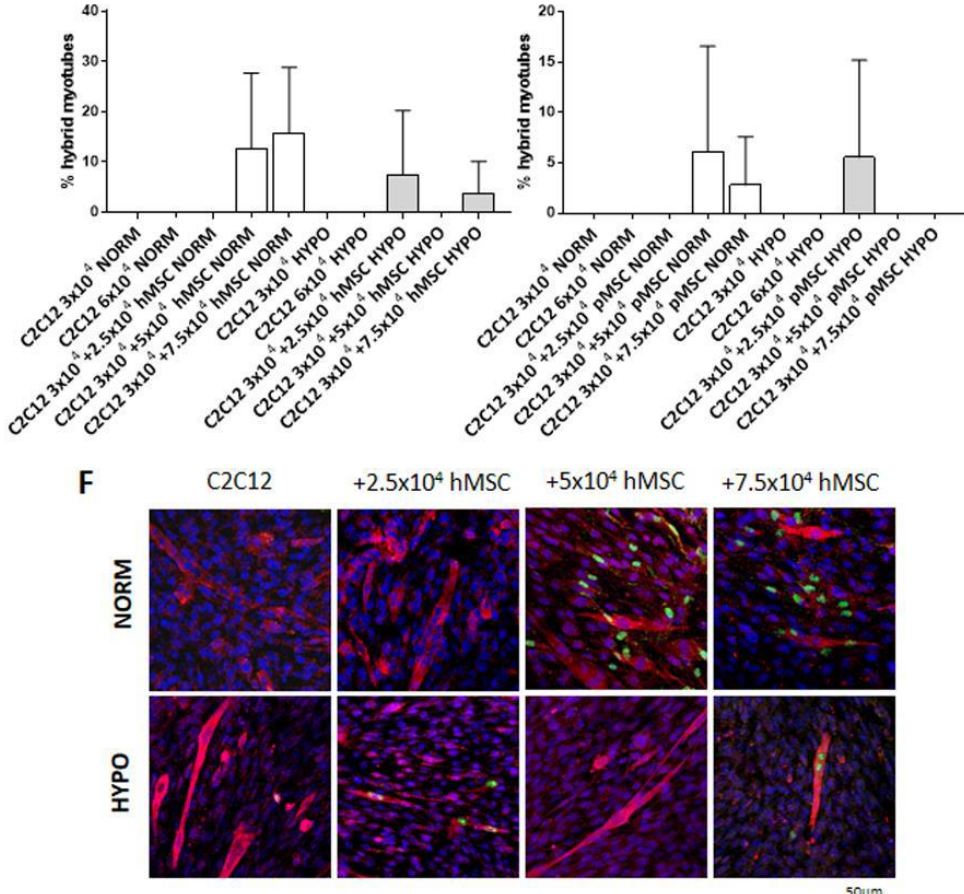
Fig. 3
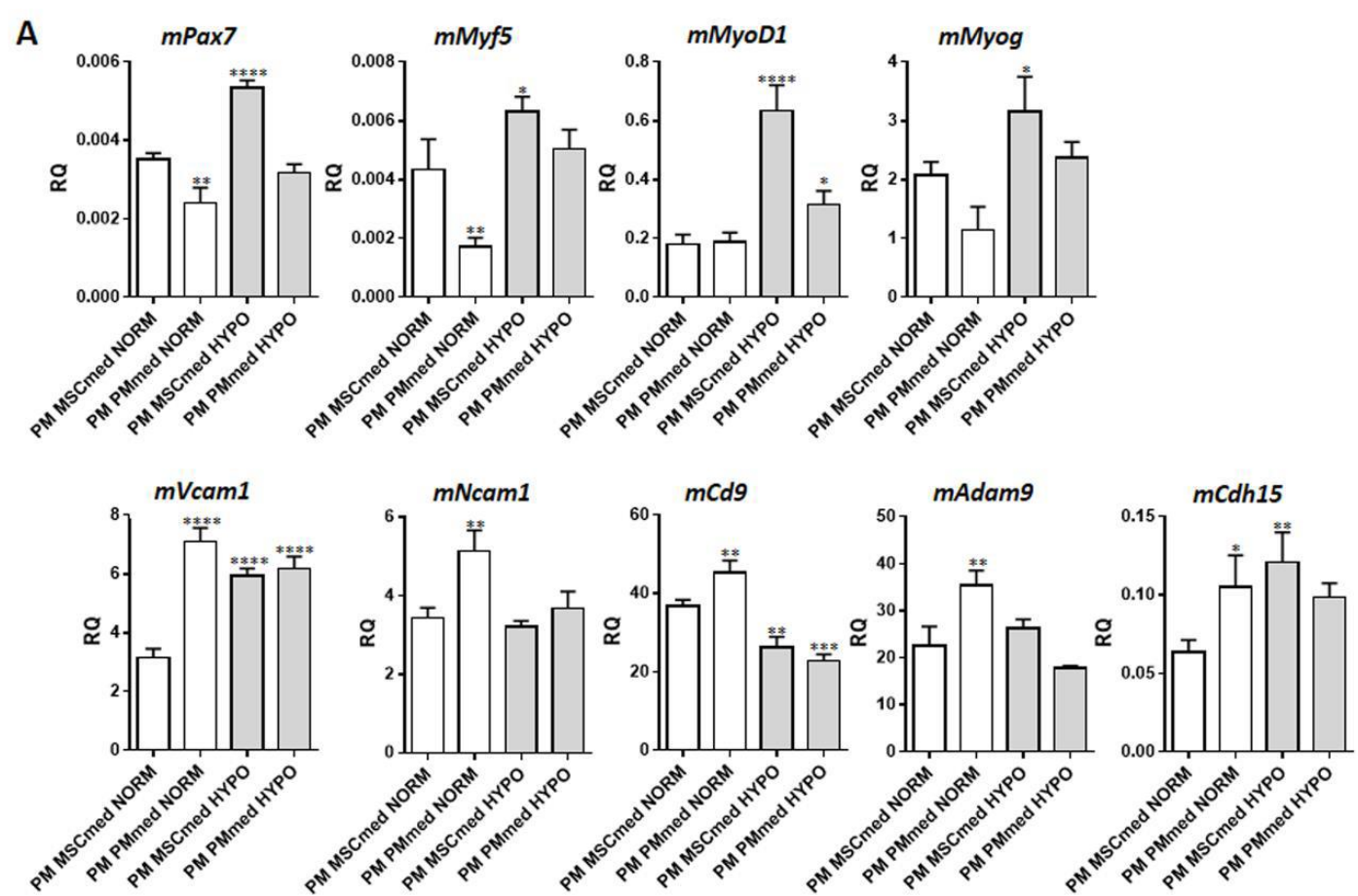

B
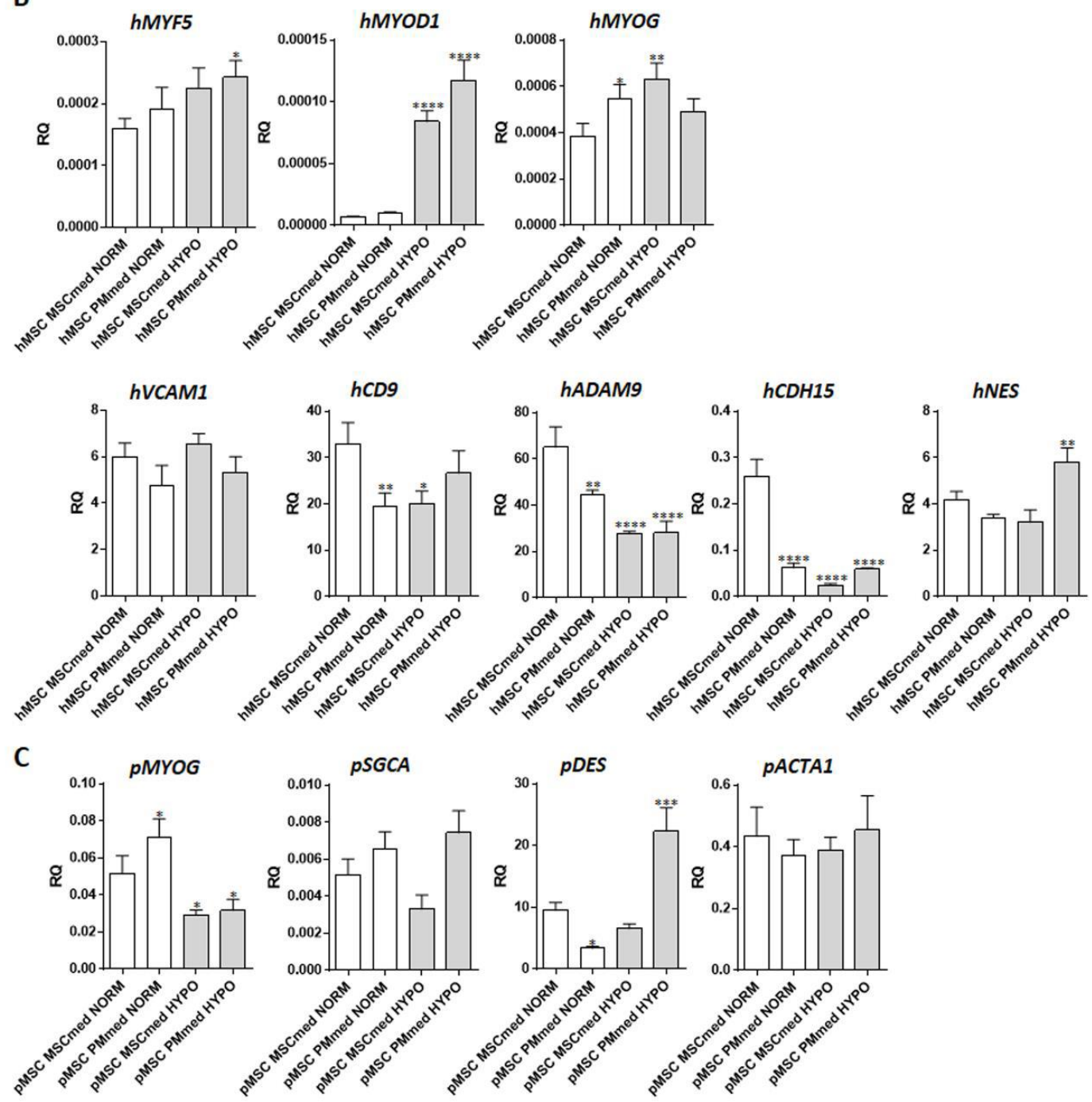
Fig. 4
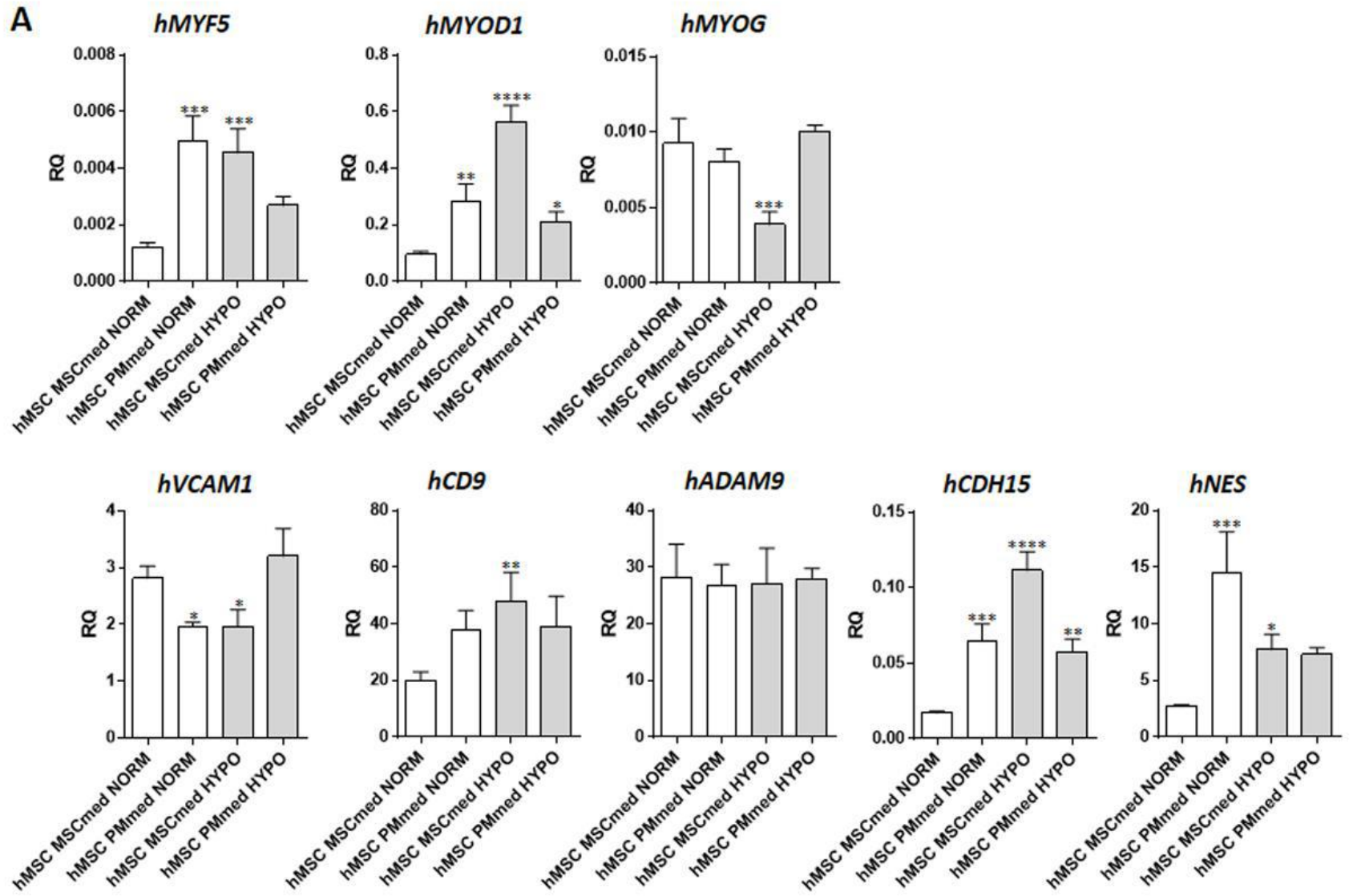

B

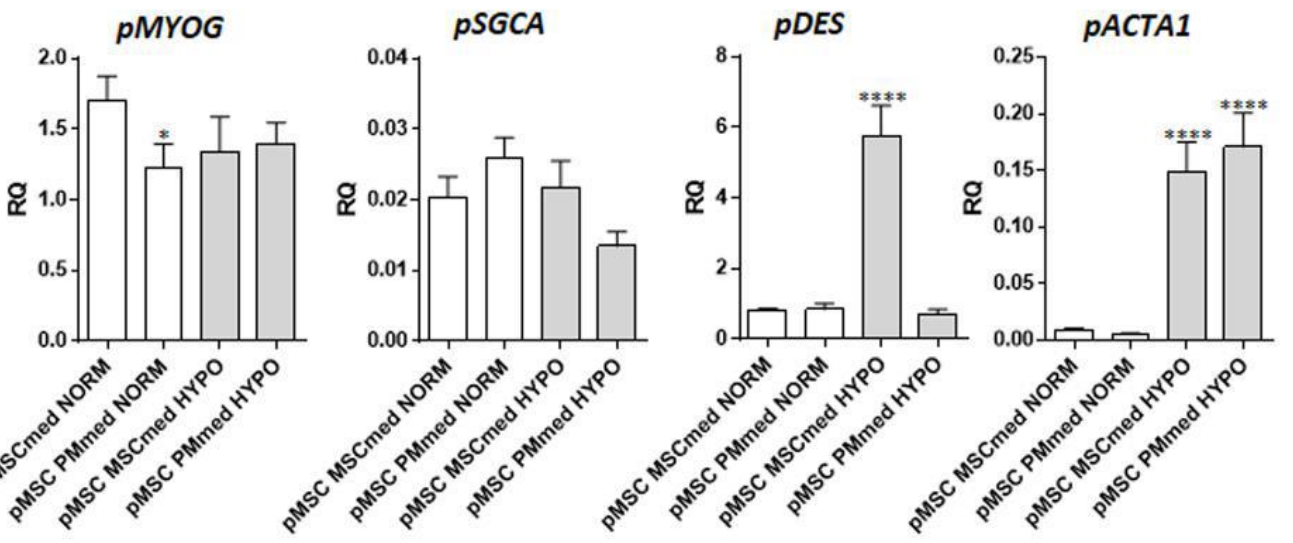


Fig. 5
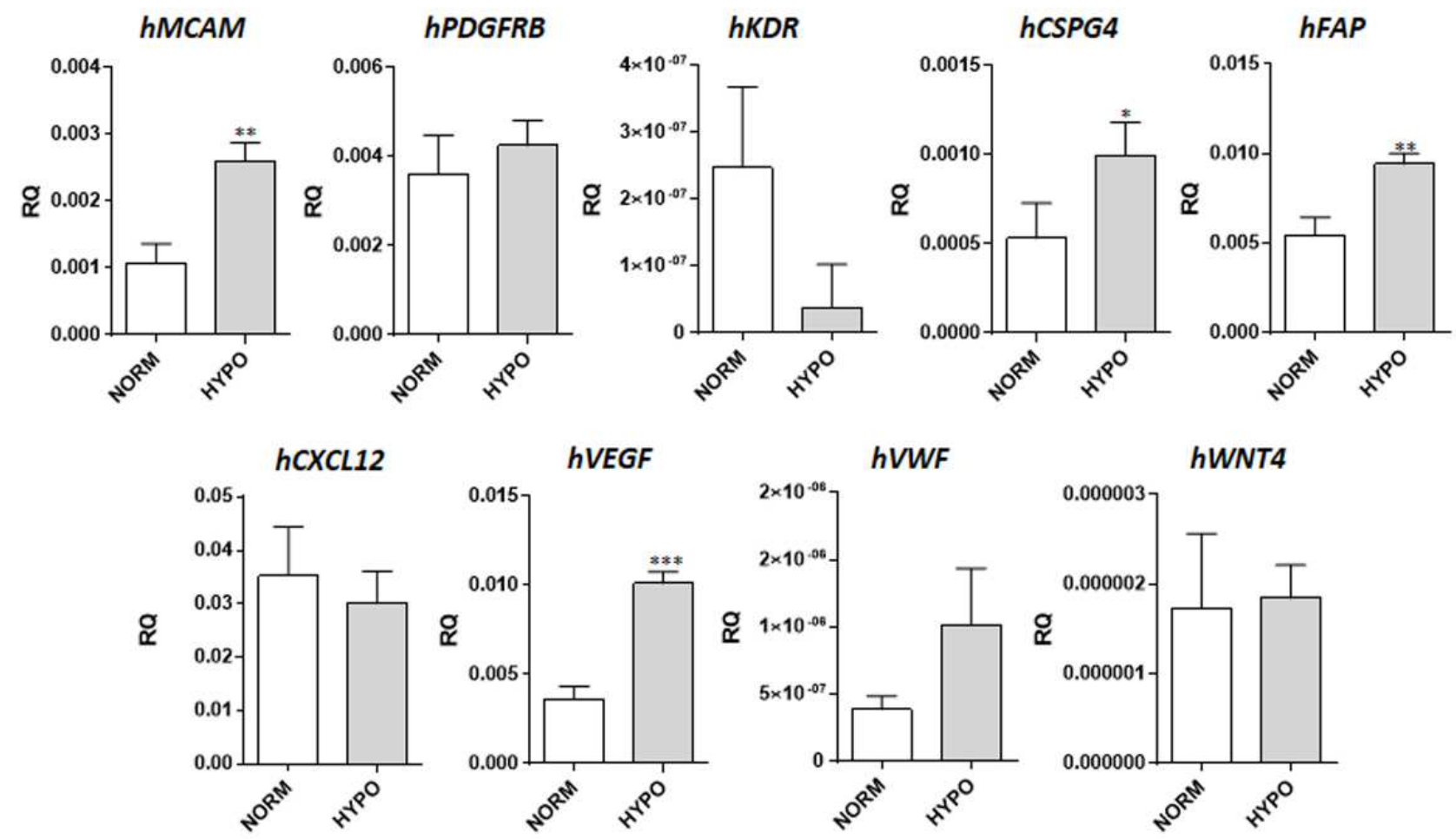
Fig. 6

A

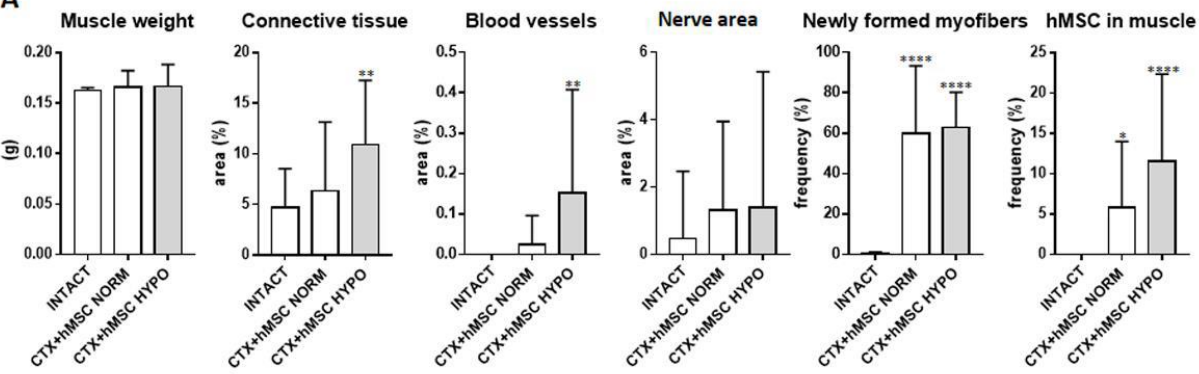

B

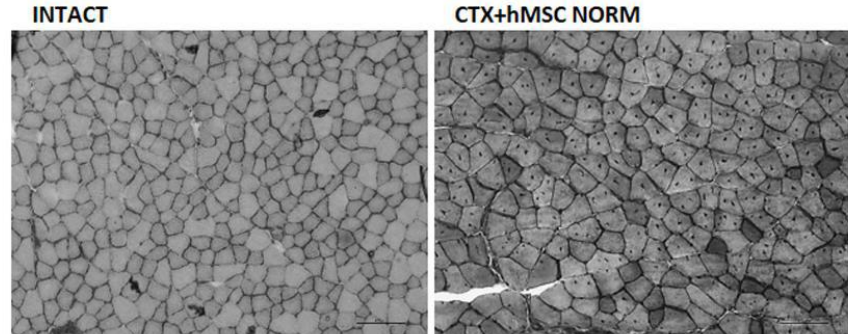

CTX+hMSC HYPO

C
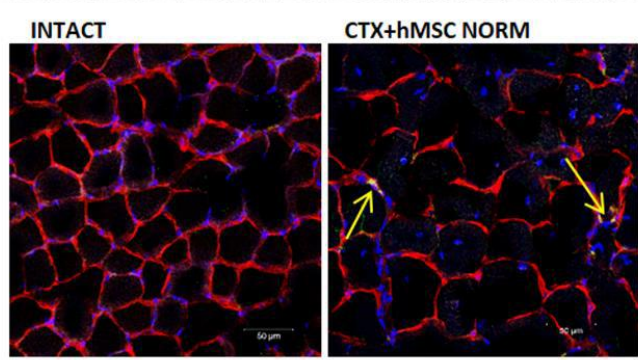

CTX+hMSC HYPO
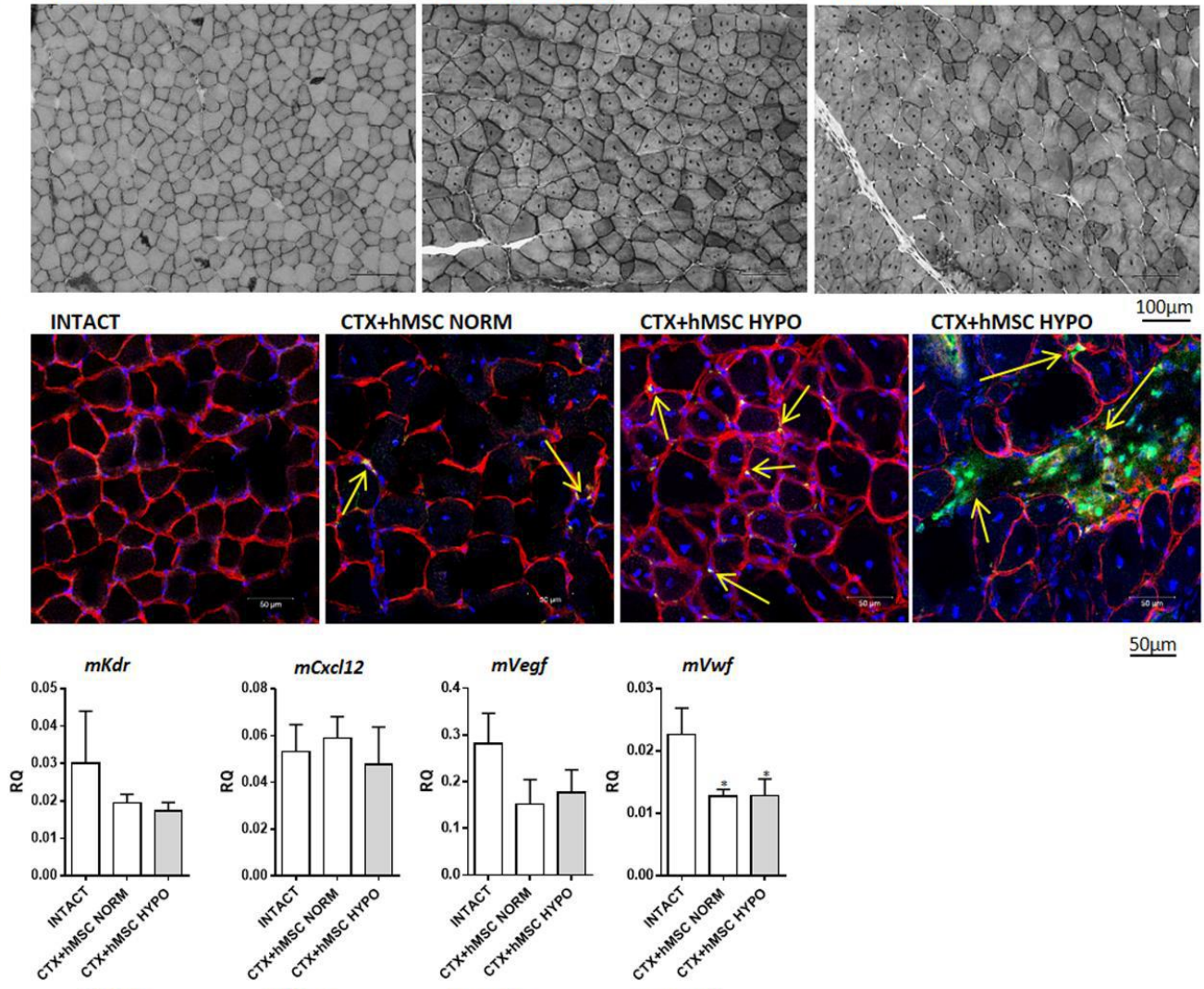

CTX+hMSC HYPO $100 \mu \mathrm{m}$

E
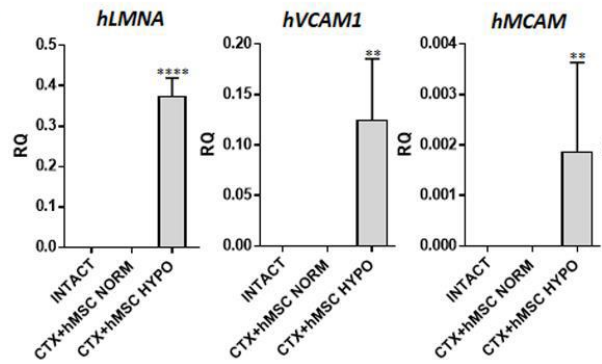

${ }_{0.03} m V w f$
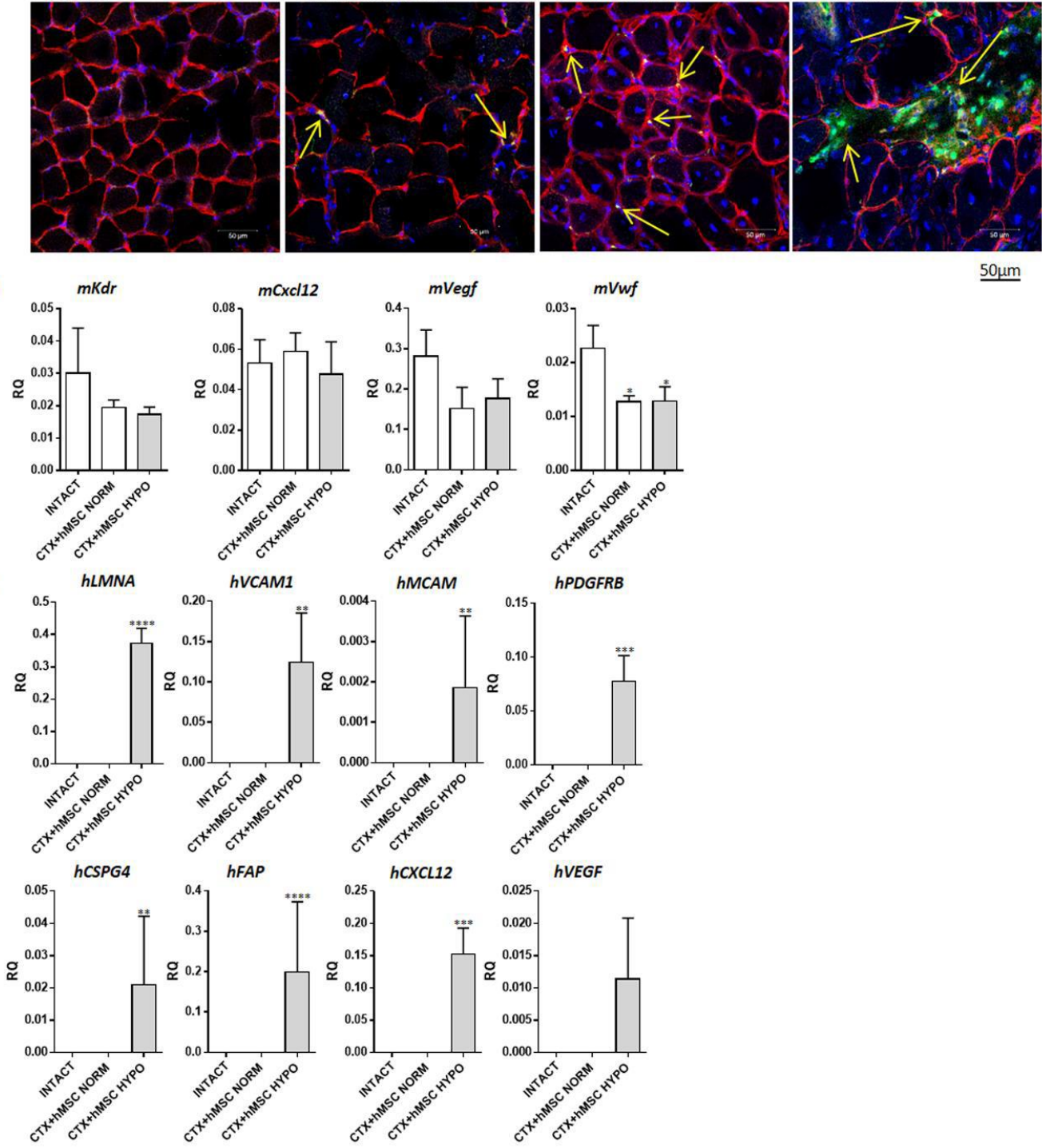


\section{Figures}

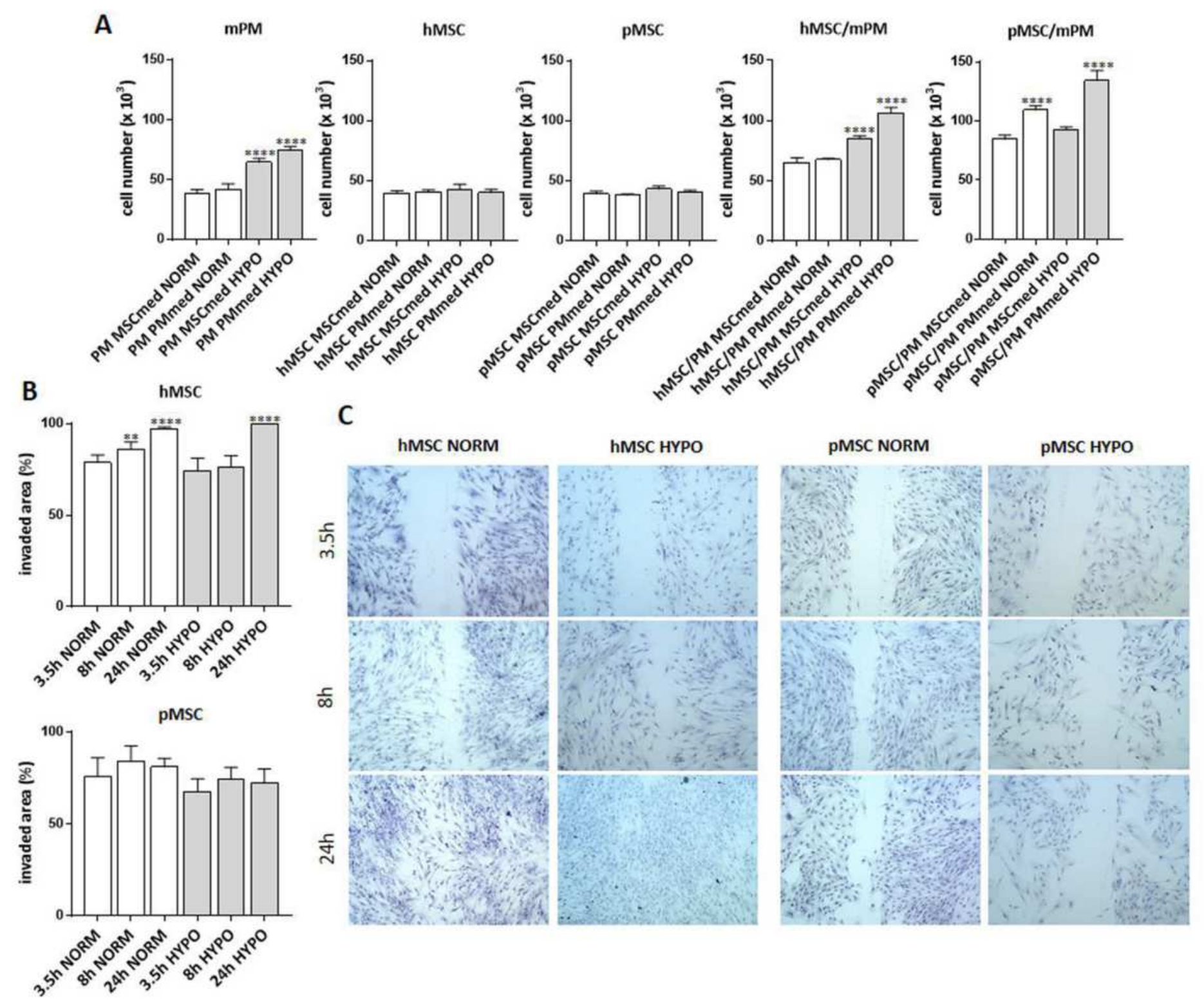

Figure 1

Cell proliferation and migration under normoxic and hypoxic conditions. A - The number of mouse primary myoblasts (mPM), human bone marrow-derived mesenchymal stromal cells (hMSC), pig bone marrow-derived mesenchymal stromal cells (pMSC), cells in co-cultures of hMSC and mPM, and cells in co-cultures of pMSC and mPM, cultured in two types of medium: MSCmed and PMmed, under normoxic (NORM) or hypoxic (HYPO) conditions. B - the invaded area measured in scratch wound healing assay of hMSC and pMSC cultured in MSCmed under normoxic and hypoxic conditions. $\mathrm{C}$ - the scratch wound healing assay of hMSC and pMSC cultured in MSCmed under normoxic and hypoxic conditions. P-value: $\star<0.05 ; * \star<0.01 ; * \star *<0.001 ; * \star \star * * 0.0001$. 


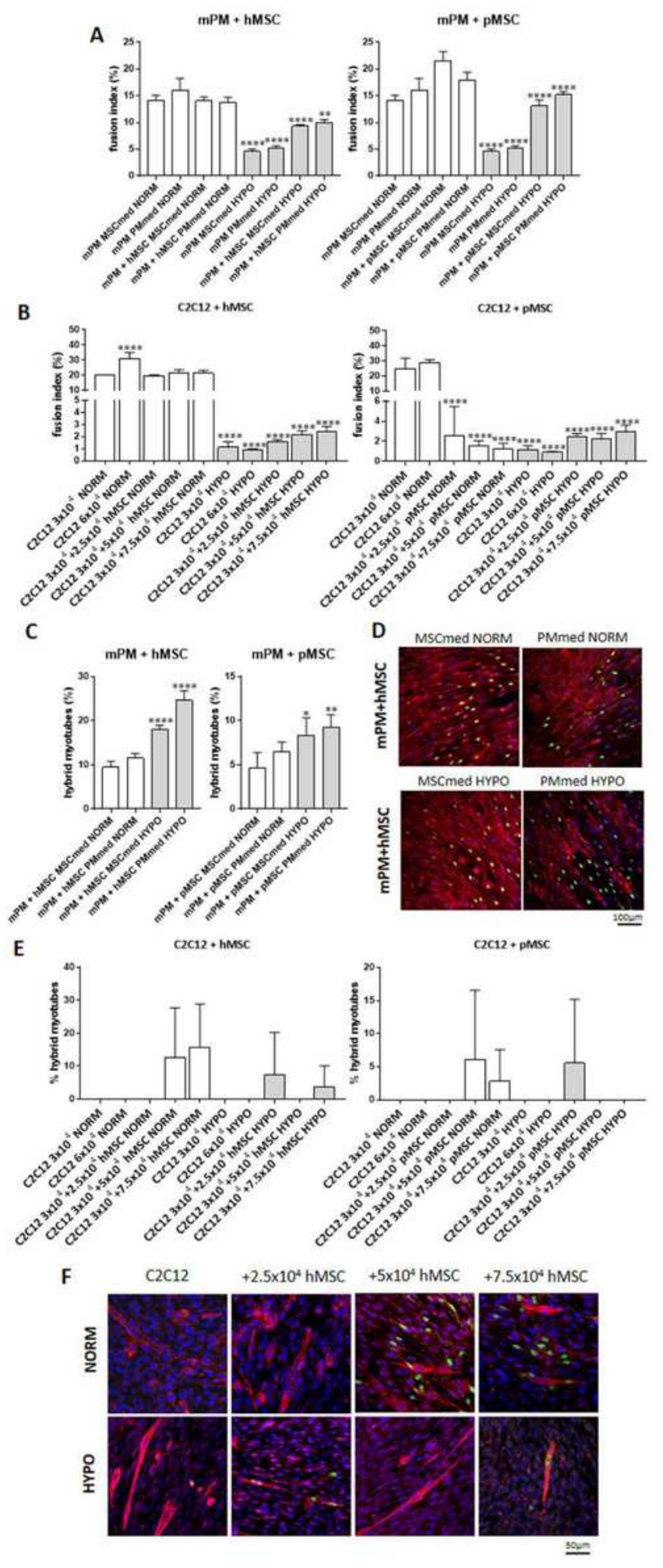

\section{Figure 2}

The fusion index and hybrid myotubes presence in either human bone marrow-derived mesenchymal stromal cells (hMSC) or pig bone marrow-derived mesenchymal stem cells (pMSC) co-culture with myoblasts: mouse primary myoblasts (mPM) or $\mathrm{C} 2 \mathrm{C} 12$ myoblasts. A - the fusion index of mPM and hMSC or pMSC co-cultured in MSCmed or PMmed under normoxic (NORM) or hypoxic (HYPO) conditions. B - the fusion index of $\mathrm{C} 2 \mathrm{C} 12$ myoblasts and hMSC or pMSC co-cultured in $3: 2.5 ; 3: 5 ; 3: 7.5$ 
ratio, in $\mathrm{C} 2 \mathrm{C} 12 \mathrm{med}$, under normoxic (NORM) or hypoxic (HYPO) conditions. C - the percentage of hybrid myotubes in mPM and hMSC or pMSC co-cultures in MSCmed or PMmed under normoxic (NORM) or hypoxic (HYPO) conditions. D - the immunolocalization of hybrid myotubes in mPM and hMSC cocultures, red - skeletal myosin, blue - cell nuclei, green human cell nuclei. E - the percentage of hybrid myotubes in $\mathrm{C} 2 \mathrm{C} 12$ and hMSC or pMSC co-cultures in $\mathrm{C} 2 \mathrm{C} 12$ med under normoxic (NORM) or hypoxic (HYPO) conditions. F - the immunolocalization of hybrid myotubes in $\mathrm{C} 2 \mathrm{C} 12$ and hMSC co-cultures, red - skeletal myosin, blue - cell nuclei, green human cell nuclei. P-value: $*<0.05 ; * \star<0.01 ; * \star \star<0.001 ; * \star \star \star$ $<0.0001$. 

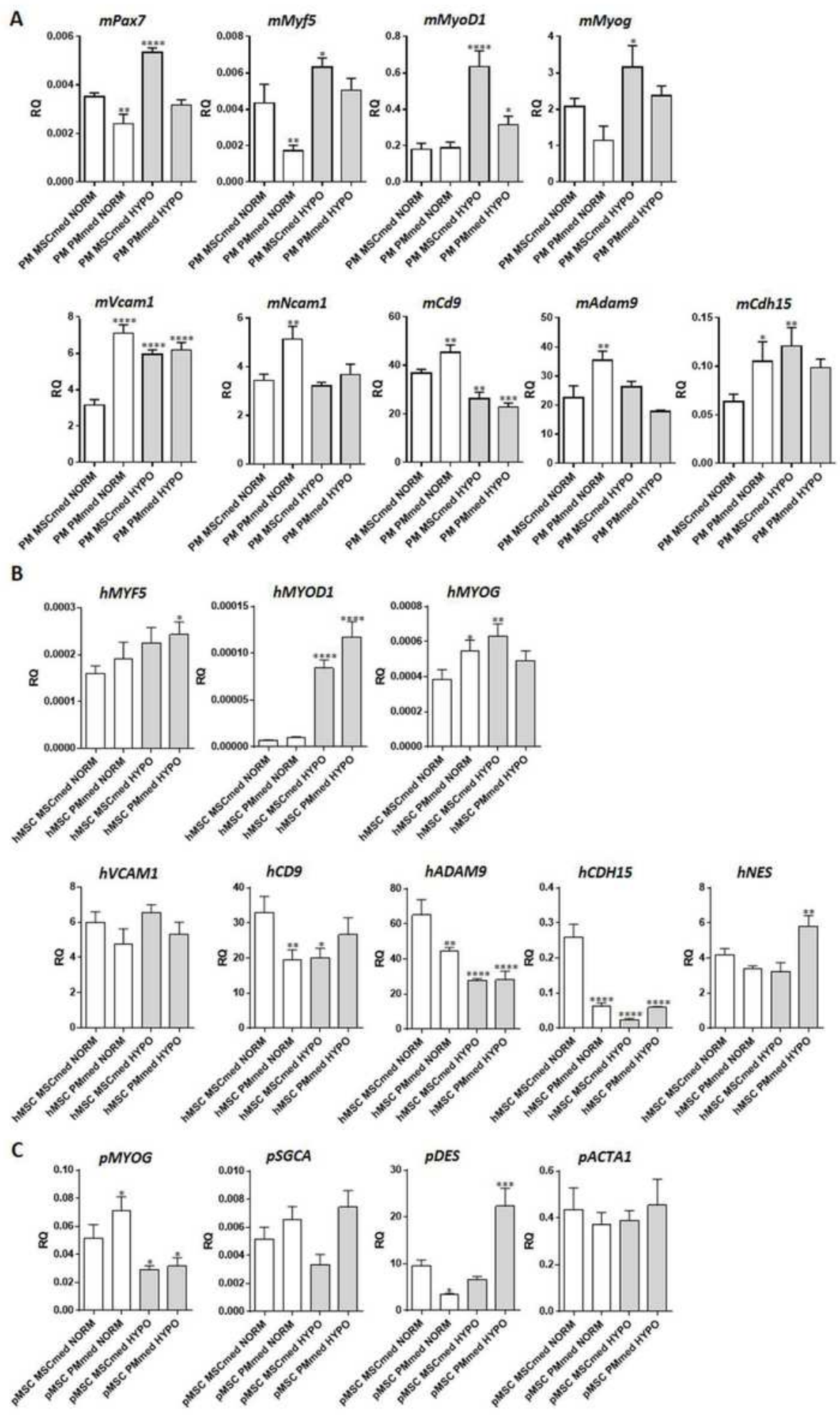

\section{Figure 3}

The expression of selected markers in cell cultures. A - the level of transcripts encoding PAX7, MYF5, MYOD1, myogenin (MYOG), VCAM1, NCAM1, CD9, ADAM9, m-cadherin (CDH15) in mouse primary myoblasts (mPM) cultured in PMmed or MSCsmed under normoxic (NORM) or hypoxic (HYPO) conditions. B - the level of transcripts encoding MYF5, MYOD1, myogenin (MYOG), VCAM1, CD9, ADAM9, m-cadherin (CDH15), nestin (NES) in human bone marrow-derived mesenchymal stromal cells 
(hMSC) cultured in PMmed or MSCsmed under normoxic (NORM) or hypoxic (HYPO) conditions. C - the level of transcripts encoding myogenin (MYOG), a-sarcoglycan (SGCA), desmin (DES), and actin a1 (ACTA1) in pig bone marrow-derived mesenchymal stem cells (pMSC) cultured in PMmed or MSCsmed

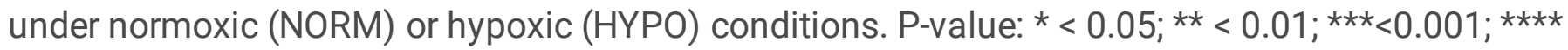
$<0.0001$.
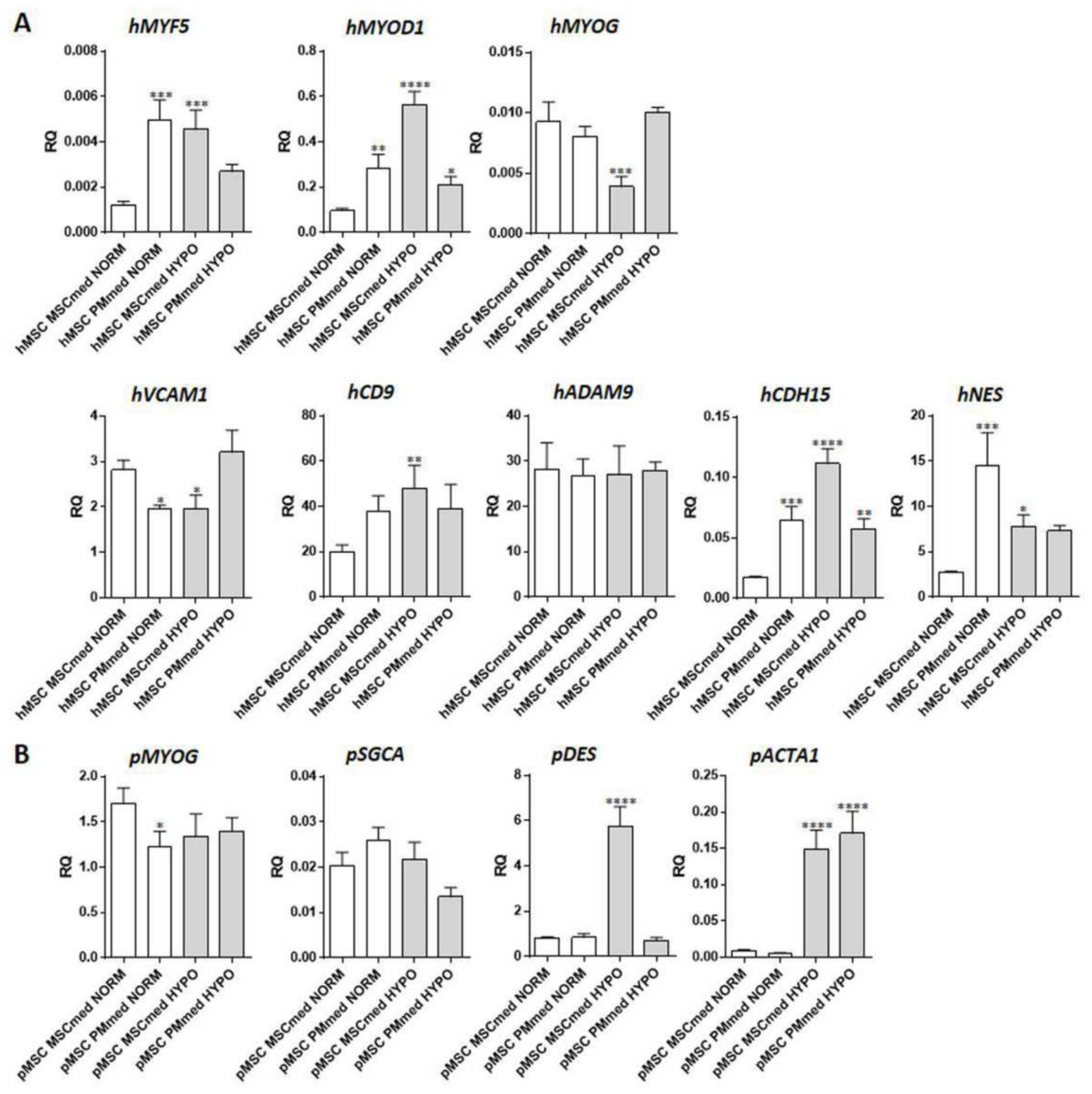

Figure 4 
The expression of selected markers in cell co-cultures. A - the level of human transcripts encoding MYF5, MYOD1, myogenin (MYOG), VCAM1, CD9, ADAM9, m-cadherin (CDH15), nestin (NES) in co-cultures of mouse primary myoblasts (mPM) and human bone marrow-derived mesenchymal stromal cells (hMSC) in PMmed or MSCsmed under normoxic (NORM) or hypoxic (HYPO) conditions. B - the level of pig transcripts encoding myogenin (MYOG) SGCA, desmin (DES), and actin a1 (ACTA1) in mPM and pig bone marrow-derived mesenchymal stem cells ( $\mathrm{PMSC}$ ) co-cultured in PMmed or MSCsmed under normoxic (NORM) or hypoxic (HYPO) conditions. P-value: * $<0.05 ; * \star<0.01 ; * \star *<0.001 ; * \star * *<0.0001$.
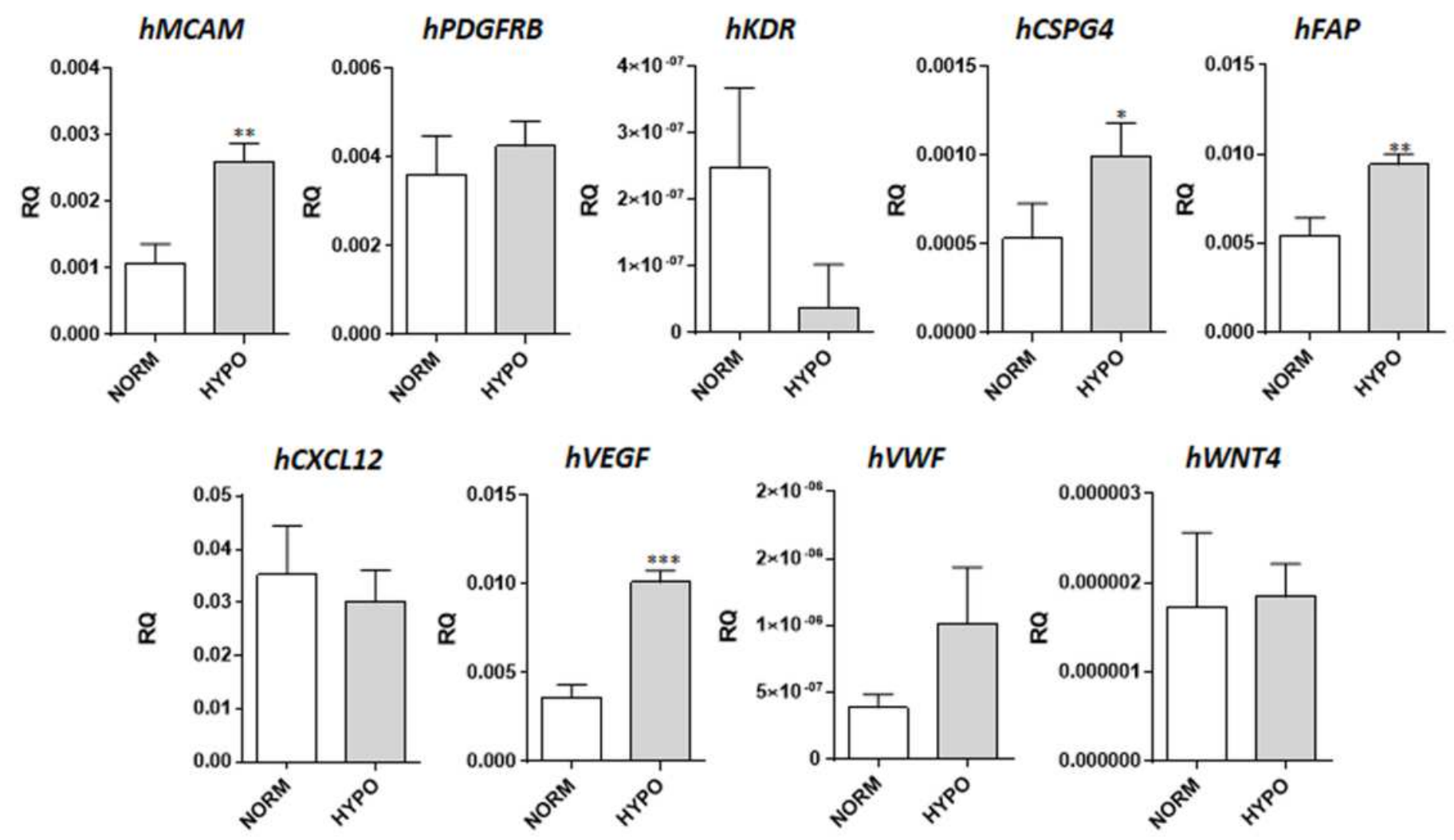

\section{Figure 5}

The level of selected markers expression in human bone marrow-derived mesenchymal stromal cells (hMSC) cultured in MSCsmed under normoxic (NORM) or hypoxic (HYPO) conditions. P value: * $<0.05$; ** $<0.01 ; * \star *<0.001 ; * \star \star \star *<0.0001$. 


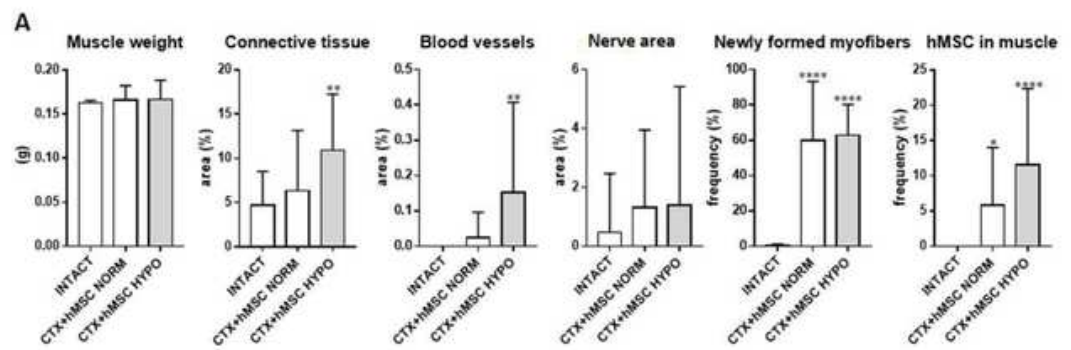

B

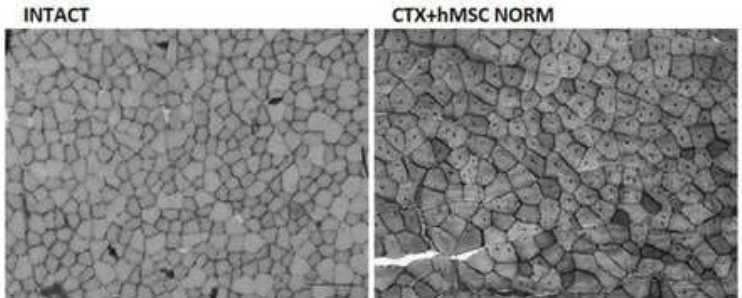

CTX+hMSC HYPO
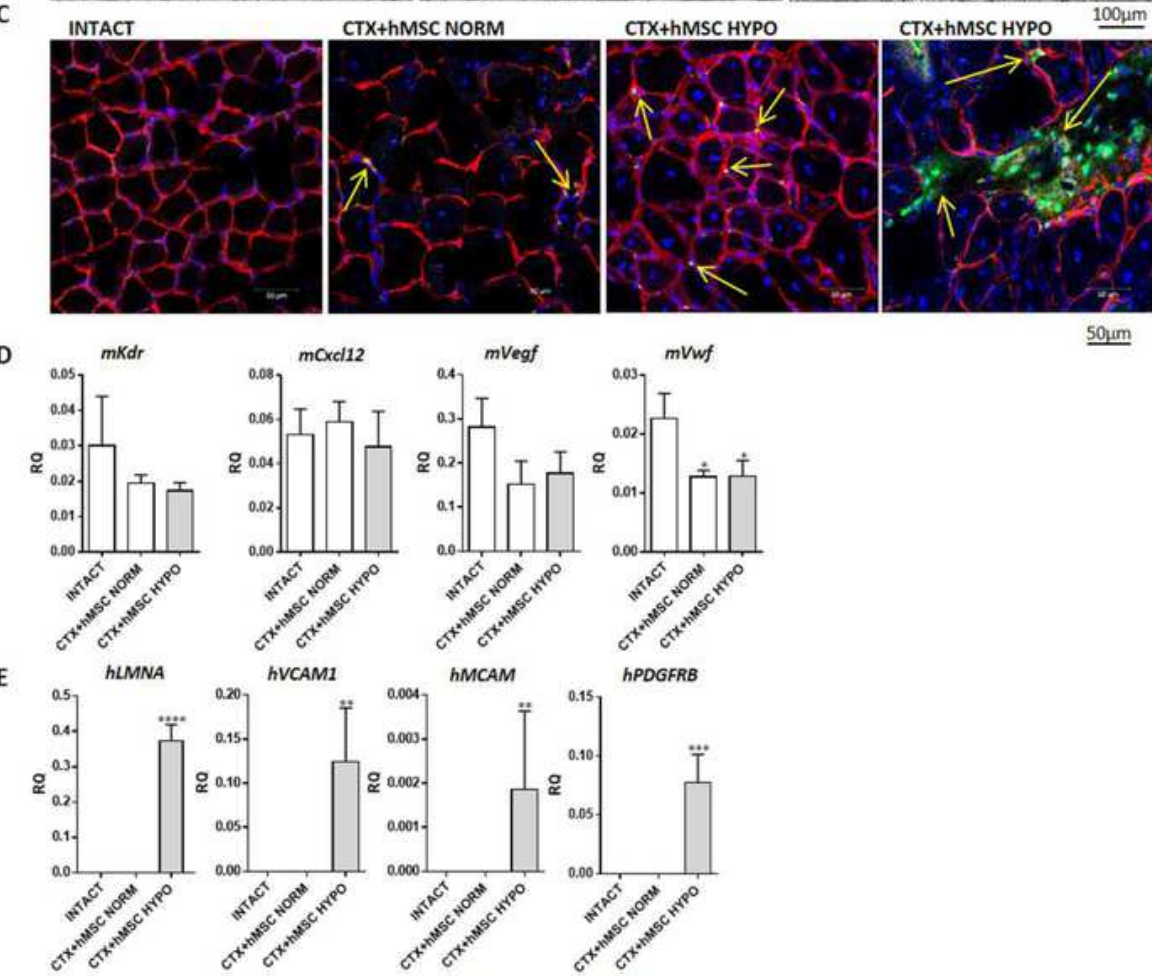

hPDGFRB
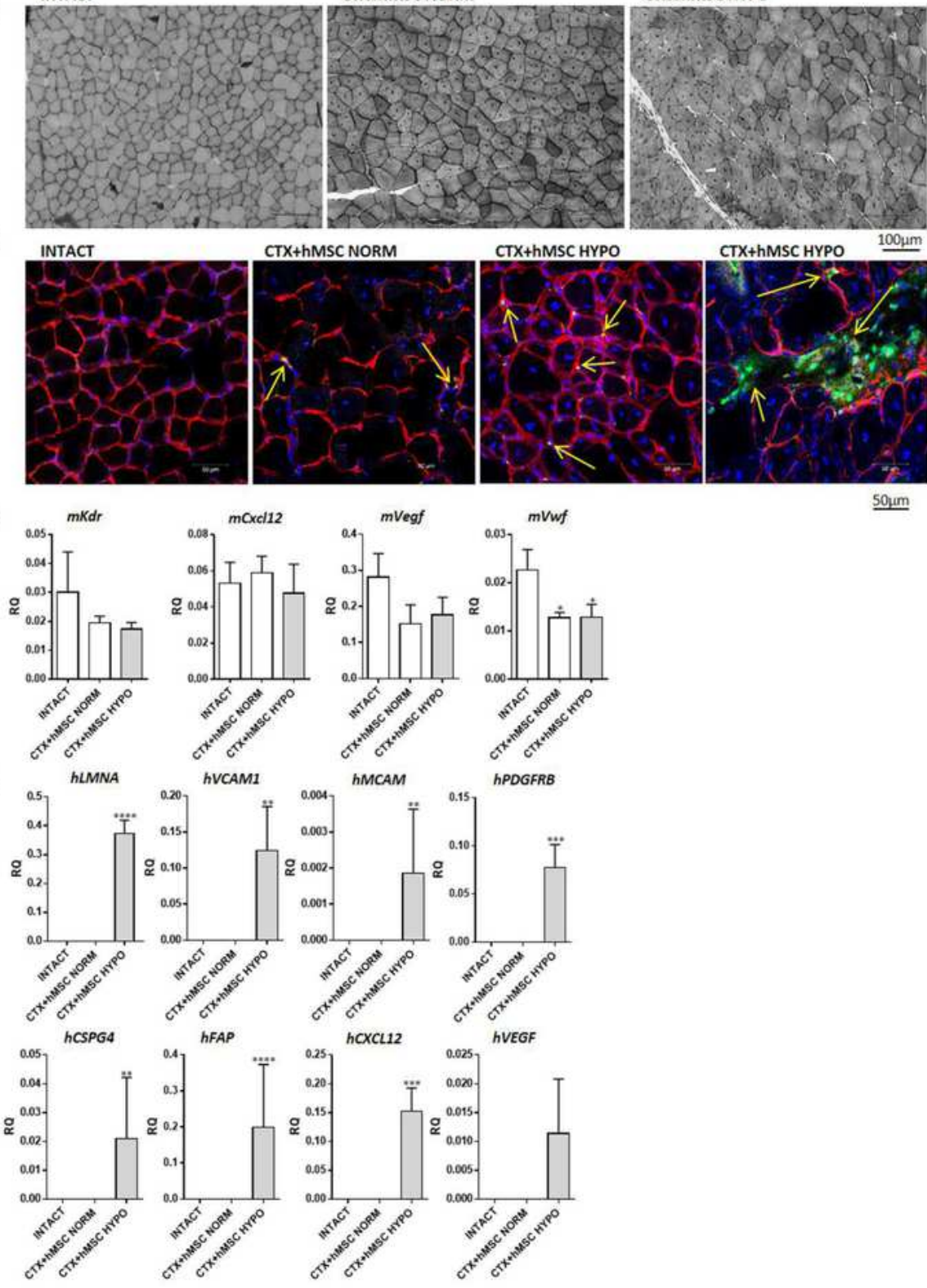

Figure 6

The skeletal muscle regeneration after human bone marrow mesenchymal stromal cells (hMSC) transplantation. The hMSCs were cultured under normoxic (NORM) or hypoxic (HYPO) conditions and injected into cardiotoxin (CTX) injured muscles. A - the skeletal muscle weight, the area of connective tissue, blood vessels, nerves, and frequency of new myofibers in intact muscles or muscles injured (CTX) and transplanted with hMSC cultured either under normoxic (NORM) or hypoxic (HYPO) conditions. B - 
histology of intact muscles or in muscles injured (CTX) and transplanted with hMSC cultured under normoxic (NORM) or hypoxic (HYPO) conditions. C - localization of transplanted cells (blue - nuclei, red - laminin, green - human nuclei) in intact muscles or muscles injured (CTX) and transplanted with hMSC cultured under normoxic (NORM) or hypoxic (HYPO) conditions. D - the expression of selected mouse transcripts in intact muscles or muscles injured (CTX) and transplanted with hMSC cultured under normoxic (NORM) or hypoxic (HYPO) conditions. E - the expression of selected human transcripts in intact muscles or muscles injured (CTX) and transplanted with hMSC cultured under normoxic (NORM) or hypoxic (HYPO) conditions. P-value: $*<0.05 ; * \star<0.01 ; * \star *<0.001 ; * \star \star *<0.0001$. 